\title{
Dynamic formulation for humanitarian response operations incorporating multiple organisations
}

Citation for published version (APA):

Rodriguez-Espindola, O., Albores, P., \& Brewster, C. (2018). Dynamic formulation for humanitarian response operations incorporating multiple organisations. International Journal of Production Economics, 204, 83-98. https://doi.org/10.1016/.i.jpe.2018.07.023

Document status and date:

Published: 01/10/2018

DOI:

10.1016/j.ijpe.2018.07.023

Document Version:

Publisher's PDF, also known as Version of record

Document license:

Taverne

Please check the document version of this publication:

- A submitted manuscript is the version of the article upon submission and before peer-review. There can be important differences between the submitted version and the official published version of record.

People interested in the research are advised to contact the author for the final version of the publication, or visit the DOI to the publisher's website.

- The final author version and the galley proof are versions of the publication after peer review.

- The final published version features the final layout of the paper including the volume, issue and page numbers.

Link to publication

\footnotetext{
General rights rights.

- You may freely distribute the URL identifying the publication in the public portal. please follow below link for the End User Agreement:

www.umlib.nl/taverne-license

Take down policy

If you believe that this document breaches copyright please contact us at:

repository@maastrichtuniversity.nl

providing details and we will investigate your claim.
}

Copyright and moral rights for the publications made accessible in the public portal are retained by the authors and/or other copyright owners and it is a condition of accessing publications that users recognise and abide by the legal requirements associated with these

- Users may download and print one copy of any publication from the public portal for the purpose of private study or research.

- You may not further distribute the material or use it for any profit-making activity or commercial gain

If the publication is distributed under the terms of Article $25 \mathrm{fa}$ of the Dutch Copyright Act, indicated by the "Taverne" license above, 


\title{
Dynamic formulation for humanitarian response operations incorporating multiple organisations
}

\author{
Oscar Rodríguez-Espíndola ${ }^{\mathrm{a}, *}$, Pavel Albores ${ }^{\mathrm{a}}$, Christopher Brewster ${ }^{\mathrm{b}}$ \\ a Aston Business School, Aston University, Birmingham, UK \\ ${ }^{\mathrm{b}}$ Data Science Group, Toegepast-Natuurwetenschappelijk Onderzoek (TNO), The Netherlands
}

\section{A R T I C L E I N F O}

\section{Keywords:}

Emergency logistics

Multiple objective programming

Disaster response

Resource allocation

\begin{abstract}
A B S T R A C T
Disasters represent a significant challenge for countries globally. Balancing human and material resources during these situations is not a trivial issue, and that is further complicated by the participation of several actors at multiple periods. However, there is an absence of articles considering the importance of deploying only the required organisations for response activities depending on the conditions and the stage of the disaster. This research proposes a dynamic model to support disaster response which incorporates human and material resources from multiple organisations. The multi-modal, multi-commodity optimisation model supports resource allocation and relief distribution decisions through the maximisation of the level of service provided to disaster victims and the minimisation of cost. The model is the first dynamic formulation in the literature with the ability to optimise the number, type and stage of deployment of organisations required according to the circumstances of the emergency. The model has been applied to two major floods that have occurred in Mexico in recent years. Each case was tested using three different scenarios to investigate the ability of the model to handle different conditions. The results of both cases were compared to scenarios with independent participation from each organisation and an instance capturing the real decisions made by Mexican authorities. The results showed the inefficiency stemming from independent decision-making, an excess of actors involved in the real instances of both cases, the applicability of the model to different circumstances, and the value of the ability to modify the number of organisations involved per stage.
\end{abstract}

\section{Introduction}

The increased frequency and magnitude of natural disasters has shown how vulnerable countries and regions around the world are (Roh et al., 2015; Whybark, 2007). Disaster management needs to be organised and responsive (Tatham and Kovacs, 2010), with clear civil protection plans in place to achieve the speedy delivery of supplies to support affected regions (Chakravarty, 2011). These plans have to consider the interaction between government organisations and their collaboration with non-governmental organisations, civil organisations, private firms, and even foreign governments (Kunz et al., 2014; Tatham and Kovacs, 2010).

The allocation of resources for disaster response activities has been identified as a priority in the literature (Holguín-Veras et al., 2014). Research on humanitarian logistics is heavily focused on the problem of avoiding shortages of relief items, but little has been written about the excess of disaster response. The usual reaction of any government after a disaster is to send every available organisation to provide support, which can lead to congestion becoming a major challenge, as shown by recent events (See Nogami and Yoshida, 2014). This paper contributes to the resource allocation challenge by examining shortages and excess. The objective of this research is to design a dynamic optimisation model to support relief distribution and resource allocation which incorporates resources from multiple organisations. The model balances the cost and fill rate of products and services to provide solutions. The paper is organised as follows: Section 2 introduces a review of the main contributions in the literature on relief distribution and resource allocation. The design of the model is explained in Section 3, while Section 4 elaborates on the application of the model to two real-world situations experienced in México. Section 5 contains an evaluation of the performance of the model and a discussion of the main results, and section 6 draws conclusions about this research.

\section{Literature review}

This paper proposes a method to support post-disaster operations in

\footnotetext{
* Corresponding author.

E-mail address: o.rodriguez-espindola@aston.ac.uk (O. Rodríguez-Espíndola).
} 
collaboration with different organisations. To clarify the contribution of this research, it is important to introduce the relevant concepts and to review previous articles. The literature review presented includes mathematical models for relief distribution and resource allocation.

\subsection{Disaster management}

Disaster management represents activities performed prior, during, and following disasters aimed at minimising the impact on vulnerable populations and enhancing recovery. Activities and priorities shift over time based on the circumstances and the disaster phase. Mitigation, preparedness, response, and recovery represent the relevant phases experienced during disaster management (Drabek and Hoetmer, 1991). These phases are a continuous cycle and often overlap. Prior to the occurrence of the disaster, mitigation and preparedness can be undertaken. Mitigation includes activities aimed at reducing the risk of disaster occurrence, whereas the preparedness phase is when activities are planned and resources are gathered to protect the population (Caunhye et al., 2012). Following the disaster, response and recovery take place. Response is related to performing activities and deploying resources to reduce the impact of the disaster until the threat has passed (Altay and Green, 2006). After the immediate threat, recovery is the stage in which society is returned to normal conditions, although less research has been focused on this phase (Altay and Green, 2006).

Gupta et al. (2016) emphasise the need to develop solutions which integrate different activities. The research in this paper is focused on disaster response activities such as resource allocation and relief distribution. These activities involve a large number of different organisations providing direct support to victims during their time of most dire need.

\subsection{Previous work in relief distribution}

Relief distribution refers to the swift and efficient dispatch of commodities to affected areas (Özdamar et al., 2004). Despite the existence of articles proposing methods based on appropriate objective functions for humanitarian operations (See Duhamel et al., 2016; Holguín-Veras et al., 2013), it is difficult to deal with the complexities associated with emergencies using a single performance measure. Therefore, some authors have suggested the use of multi-objective optimisation. Tirado et al. (2014) use a lexicographic approach to manage the delivery of relief, using a two-phase flow model. At the first level, the difference between the aid planned to be shipped and the aid sent in reality is minimised; and time, cost and the highest unsatisfied demand is dealt with in the second phase. Ransikarbum and Mason (2016b) address supply distribution and network restoration during response and recovery. The model maximises equity, minimises unsatisfied demand, and minimises restoration cost. The authors explore the possibility of using pooled budgets from different activities; an approach that could be extrapolated to pool different types of resources, which would be beneficial for humanitarian organisations. Nevertheless, this could create problems in terms of jurisdiction and the organisation's identity. More importantly, the combination of resources implies the deployment of all of the organisations, which can lead to congestion and idle resources. Ransikarbum and Mason (2016a) build upon this, considering bounded rationality and incomplete information to provide a goal programming model with the same objectives. Also, considering the need to undertake repairs for subsequent distribution, Liberatore et al. (2014) present a distribution-recovery model for disasters, with the objective of maximising the total reached demand, minimising the maximum distance from reliability, security, and demand satisfaction from its ideal value, and minimising the sum of the attribute distances. Meanwhile, Sha-lei et al. (2014) incorporate stochastic demands, reliability of the distribution network and Bayesian updates for disaster scenario information. The model proposed minimises total time, unmet demand, and cost.
The models presented so far are static (i.e. considering one period). During emergency situations, however, the evolution of events and the inter-temporal factors must be included (Holguín-Veras et al., 2013). There are contributions considering relief distribution as an ongoing activity with multiple periods. Combining multi-criteria optimisation with objectives designed for humanitarian logistics, Huang et al. (2015) address human suffering through the maximisation of lifesaving utility (i.e. preference of resources), the minimisation of delay cost (similar to deprivation cost), and the minimisation of the difference between the demand fill rate and the ideal demand rate. However, the model is focused on one-off demand products only (Balcik et al., 2008) and also disregards collaboration among different organisations. Incorporating coordination and uncertainty in information, Adivar and Mert (2010) propose a collection-distribution plan of international relief items using fuzzy logic. The model minimises cost and maximises the minimum credibility of international organisations to deliver relief items on time. Despite the emphasis on the importance of collaboration, the article incorporates material allocation only and does not consider the interaction of different national organisations.

\subsection{Previous work in resource allocation}

There are essential resources during emergencies other than relief products, such as people, equipment, and vehicles. The allocation and deployment of resources is a relevant logistical activity (Anaya-Arenas et al., 2014) because it allows resources to be shared among organisations, which is an effective approach for disaster operations (Balcik et al., 2010). Coordination, collaboration, and communication among stakeholders are key to designing useful response plans for natural disasters (Kumar and Havey, 2013).

There are research papers managing resources on helicopter missions (Barbarosoğlu et al., 2002), rescue equipment (Chang et al., 2007), volunteers (Lassiter et al., 2015), and medical teams (Lei et al., 2015). These articles provide a valuable contribution to essential disaster response activities, but relief distribution has not been integrated into these models.

Arora et al. (2010) consider coordination among regions for the allocation and redistribution of medical aid. The model proposed minimises the cost associated with the policy selected. Meanwhile, Davis et al. (2013) address coordination using cooperative warehouses. They place uncertainty in supply, demand and the possibility of disaster into a two-stage scenario-based model. The first stage is focused on prepositioning decisions, whereas the second stage considers distribution incorporating equity of service. Altay (2013) proposes a model to allocate response personnel, facilities, supplies, and equipment to disaster-affected jurisdictions. They formulate the problem as a matching problem with two alternative objective functions: to minimise total deployment time or to minimise maximum response time. Including uncertainty in the state of the road network, Edrissi et al. (2013) present a model that coordinates agencies in charge of strengthening structures around vulnerable areas, retrofitting transportation links, and locating and equipping emergency response centres. The model addresses the three sub-problems individually, aiming to maximise survival rates. As shown by the models presented, resource allocation models in the literature consider several participants. However, the importance of managing resources and the number of organisations involved simultaneously are neglected.

\subsection{Research contribution}

This article introduces a novel model to support resource allocation and relief distribution during disasters. The main contributions of the model are as follows:

- Dynamic model for multiple organisations - This article proposes a multi-period model capable of optimising the number of 
organisations required for collaborative allocation and the distribution of relief products and services. Such models do not exist in the prior literature. The ability to identify which organisations are needed and the ideal time to deploy them can support successful operations.

- Inclusion of services in the model - Providing relief products and services to survivors is a priority after disasters (Kunz et al., 2014), although services have been considerably less studied. The model defines the level of service as a function of the fulfilment of relief items and services, which extends the common focus on relief items alone.

- Integration of human and material resources for relief distribution and resource allocation - The use of human resources in emergencies is essential for governmental authorities, as shown by Duhamel et al. (2016). Nevertheless, relief distribution models have commonly overlooked this dimension.

\section{Model design}

The mathematical model developed in this research considers the trade-off between the use of resources and the level of service provided. The purpose is to enable logistics decisions along with the type and number of actors involved per period. The model supports the decisionmaking regarding which organisations are required according to the conditions of the emergency.

\subsection{Problem statement}

The model was developed based on the Mexican disaster management framework. The disaster management policy in the country is built around the Civil Protection National System (SINAPROC), which operates as a coordinating body to provide guidance for participant organisations (SEGOB, 2006). There are three governmental levels involved in disaster management: local, regional, and national authorities (Rodríguez-Espíndola et al., 2018). Each level involves several organisations. There can be up to 23 participants from the government alone (SEGOB, 2006), and each organisation provides human and material resources managed at the supply facilities which are allocated to different demand areas. Fig. 1 depicts the process by which human and material resources owned by the organisations are sent to the affected region. The former include personnel with different expertise (i.e. healthcare, shelter care, distribution, and facility management), whereas the latter encompass products and vehicles.

Relief items (e.g. food, medicine, cleaning kits) are sorted in supply facilities by facility management employees and delivered to the demand areas by distribution personnel in the vehicles provided. These vehicles can be from land, air and/or water transportation, subject to availability. The items can be directly sent to affected neighbourhoods to people reluctant to evacuate, or to shelters prepared by authorities. In shelters, the products are received and managed by employees running the facilities. These people are also in charge of security, social activities and serve as liaison with disaster managers. Additionally, healthcare is also provided in shelters to treat minor illnesses and injuries. These are the same products/services provided by authorities in Mexico during disasters (SEDENA, 2010).

The high potential number of participant organisations emphasises the need to calculate the optimal combination of organisations to deploy at each period. The length of each period is an important decision that depends on the disaster and the context. For small short-term situations, periods can be short (e.g. hours or a day), but these can grow depending on the circumstances (e.g. days or a week). Additionally, the periods can be set according to policy and disaster management practices (e.g. decision times for different processes or the duration of certain replenishable relief items). The model introduces organisations as a set to incorporate their individual resources and to coordinate them. It can find the best combination of organisations to deploy to the field at every period depending on the situation, thereby preventing shortages and convergence.

De la Torre et al. (2012) discuss the difference between egalitarian and utilitarian policies used in the literature for disaster relief routing. The former considers the need for fairness and equality, whereas the latter is more focused on the use of resources. Disaster management models must consider fairness because of the human cost involved. There are a number of articles incorporating fairness in their models (See Ransikarbum and Mason, 2016a; Rennemo et al., 2014). These articles must, however, consider the perspective of the stakeholders involved. To face situations with scarce resources, as many organisations do, effectiveness and fairness has to be balanced by the

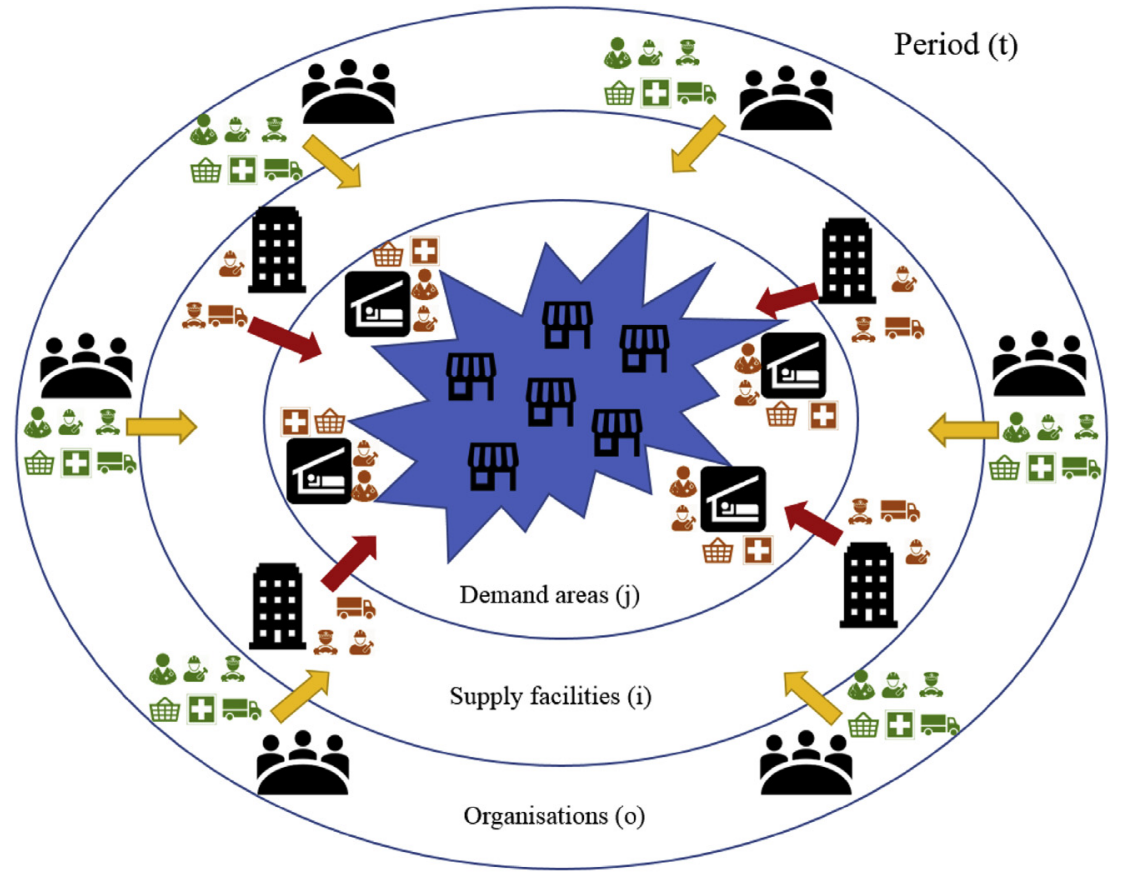

Fig. 1. Problem description. 
appropriate use of resources (i.e. utilitarian). This research introduces a combination of utilitarian measures with an egalitarian consideration. Efficiency, effectiveness (See Beamon and Balcik, 2008), and equity are key indicators for public services (Savas, 1978).

Cost is a key indicator for authorities in Mexico (RodríguezEspíndola and Gaytán, 2015) and is used as a measure of efficiency (See Beamon and Balcik, 2008). Organisations like the ones presented in Fig. 1 work together as part of the disaster management system in Mexico. Because of the importance of cost for decision-makers (SEDENA, 2010), the model minimises the cost of the entire system in order to use pooled resources efficiently. Additionally, cost is used to avoid congestion and excess of human resources. As the cost of each organisation is paid based on its wages, larger organisations are more expensive to deploy to the field. Therefore, the model uses only the organisations needed to satisfy demand.

Fill rate is employed as a proxy for the level of service to achieve effectiveness. As argued by Whybark (2007), often the benefits of disaster management systems can be social, therefore fill rate considers the perspective of the victims. The need for shelter, relief items, and urgent healthcare after a disaster has been stated in the literature (De la Torre et al., 2012). Thus, the model focuses on the fulfilment of products, the presence of healthcare personnel for injuries and diseases, and the presence of shelter personnel (for security and cooking, among others). These are the elements provided by authorities in Mexico during disasters (SEDENA, 2010).

Fairness has been identified as an appropriate objective for humanitarian logistics (Roh et al., 2015). The Sphere handbook states that relief products have to be distributed impartially according to the level of need (De la Torre et al., 2012), which is the reason why equity and priority have been used as measures of fairness in the literature. The former aims to provide services impartially among recipients, whereas the latter tries to give preferences based on the level of damage. Equity is the fairness measure chosen for this research because it has been used for distribution to safe areas before (See Ransikarbum and Mason, 2016a). Equity is introduced using a constraint to enforce the satisfaction of a minimum fill rate per product at every demand area every three time periods. Holguín-Veras et al. (2013) argue that the deprivation of products has an exponential impact on disaster victims, which increases with time. Balancing that argument against the potential unfeasibility of requesting complete satisfaction of needs for every period, this article proposes that a certain percentage of demand is satisfied at least every three periods. This constraint is important for isolated and peripheral areas in the affected region that could be otherwise overlooked.

\subsection{Model assumptions}

Based on the Mexican disaster management framework, a set of assumptions was made to limit model scope and to ensure a manageable set of variables. The main assumptions are as follows;

- There is one centralised decision-maker authority coordinating and overseeing response operations - One coordinating body directs the activities of different organisations, such as SINAPROC in Mexico or the Federal Emergency Management Agency (FEMA) in the United States. This is a holistic view used to find the best combination of decisions to support society.

- The organisations operate as a system - There is interest in collaboration across organisations to maximise benefits and minimise use of resources for the entire system, instead of focusing on individual entities.

- The organisations are available for deployment at every period Organisations make resources available to the coordinating body. These resources can be called upon at any given period because of the priority of disaster management over other activities.

- Information about availability of resources is up-to-date and provided in advance - The model relies on information that is available to the organisations before the disaster. This information can be shared and updated using information systems.

- There are clear policies and agreements in place for disaster management operations - A set of pre-approved supplies, suppliers, and facilities have been prepared in advance. Additionally, responsibilities and jurisdictions are clearly defined to ease collaboration.

- Once an organisation is activated, all of its resources become available - Beyond the effect on the linearity of the model, this assumption prevents the excessive heterogeneity of resources that could lead to complicated cross-organisational collaboration.

- Information is being gathered during the initial stage of the emergency - Knowledge about the conditions of the disaster is available.

- There are two types of demand areas: emergency facilities and neighbourhoods - The expected support in emergency facilities includes shelter care, healthcare, and relief goods; whereas affected neighbourhoods with non-evacuated residents are supported through the delivery of relief goods only.

\subsection{Data required for the model}

As mentioned by Mete and Zabinsky (2010), disaster management models rely on data from the stakeholders involved. The model proposed can be used either to analyse a series of scenarios varying demand to develop a disaster management policy, or during the disaster as the conditions evolve and better estimates are calculated (Whybark, 2007), using information from the needs assessment. The parameters used by the model can be classified into four groups:

- Parameters that rely on the decision-maker are determined based on expert opinion, the preferences of the decision-maker, and the conditions of the area. Standard requirements can be estimated using expert opinion so as to calculate shortages and excess of resources. These are mostly related to policy and are included to allow a degree of flexibility.

- Organisation-specific parameters include information about available resources to the organisations involved.

- Disaster-related parameters refer to information specifically related to the magnitude and conditions of the disaster. The priority of the products, for instance, is introduced based on the needs analysis. This parameter highlights which products are needed more urgently based on the circumstances, with higher values allocated to high priority items. In addition, disaster-related parameters can be used to perform a sensitivity analysis and to check if the system is robust enough to handle different situations.

- Parameters of initial conditions refer to decisions already made and resources already deployed because of preparedness policies or provided by other organisations.

\subsection{Notation and definitions}

The sets and definitions of the model are as follows:

Sets

I Supply facilities, $I=\{1,2,3, \ldots,|I|)$

J Demand areas, $J=\{1,2,3, \ldots,|J|)$

M Transportation modes, $M=\{1,2,3, \ldots,|M|)$

N $\quad$ Products, $N=\{1,2,3, \ldots,|N|)$

O Organisations, $O=\{1,2,3, \ldots,|O|)$

$\mathrm{T} \quad$ Time periods, $T=\{1,2,3, \ldots,|T|)$

Parameters determined by the decision-maker

$\alpha \quad$ Space that can be managed per employee in the supply facility $\left(\frac{m^{3}}{\text { employee }}\right)$ 
$\beta \quad$ Number of people that can be served per shelter employee ( $\left.\frac{\text { people }}{\text { employee }}\right)$

$\mathrm{cf}_{\mathrm{ijm}} \quad$ Coverage of supply facility $i$ to shelter $j$ by mode $m$, $\mathrm{cf}_{i j m}=\{0,1\}$

$\gamma_{\mathrm{m}} \quad$ Distribution personnel required per vehicle per mode $m$ ( $\left.\frac{\text { employee }}{\text { vehicle }}\right)$

$\delta \quad$ Percentage of personnel needed for partial opening of supply facilities, $0 \leq \delta \leq 1$

$\zeta \quad$ Number of days for relief distribution per period (day)

$\mu_{\mathrm{n}} \quad$ Minimum fill rate of product $n$ every three periods, $0 \leq \mu_{n} \leq 1$

$\rho_{\mathrm{m}} \quad$ Available number of trips that can be carried out per day per vehicle of mode $m\left(\frac{\text { trips }}{\text { vehicle }} /\right.$ day $)$

$\Psi$ Number of people that can be served per healthcare team $\left(\frac{\text { people }}{\text { team }}\right)$

Parameters provided by the organisations involved

$\mathrm{a}_{\mathrm{i}} \quad$ Storage capacity of supply facility $i\left(\mathrm{~m}^{3}\right)$

$\varepsilon_{\mathrm{n}} \quad$ Procurement cost per product $n\left(\frac{\$}{\text { product }}\right)$

$\eta_{\text {ot }} \quad$ Available staff from organisation $o$ for operation of supply facilities at period $t$ (employee)

$\theta_{\mathrm{ot}} \quad$ Available personnel from organisation $o$ for shelter care at period $t$ (employee)

$\kappa_{\mathrm{ot}} \quad$ Available personnel from organisation $o$ for healthcare at period $t$ (team)

$\lambda_{\text {ot }}$ Total operative personnel available per organisation $o$ at period $t$ (employee)

$\xi_{\text {ot }} \quad$ Available personnel from organisation $o$ for distribution at period $t$ (employee)

$\mathrm{pg}_{\mathrm{n}} \quad$ Number of people that can be satisfied per unit of product $n$ ( $\left.\frac{\text { people }}{\text { product }}\right)$

$\mathrm{sc}_{\mathrm{j}} \quad$ Storage capacity of the demand area $j\left(\mathrm{~m}^{3}\right)$

$\sigma_{\mathrm{ot}} \quad$ Wages paid for the activation of organisation $o$ at period $t$ (\$)

$\mathrm{tf}_{\mathrm{m}} \quad$ Weight capacity of vehicle $m\left(\frac{\mathrm{kg}}{\text { trip }}\right)$

$\tau_{\text {mot }} \quad$ Total number of available vehicles of mode $m$ per organisation $o$ at period $t$ (vehicles)

$v_{\text {not }} \quad$ Maximum number of relief of product $n$ that can be provided by organisation $o$ at period $t$ (products)

$\phi_{\mathrm{n}} \quad$ Volume per product $n\left(\frac{m^{3}}{\text { product }}\right)$

$\varphi_{\mathrm{ijm}} \quad$ Cost of delivering relief from supply facility $i$ to shelter $j$ by mode $m\left(\frac{\$}{\text { trip }}\right)$

$\Omega_{\mathrm{n}} \quad$ Weight per product $n\left(\frac{\mathrm{kg}}{\text { product }}\right)$

Disaster-specific parameters

$b_{n} \quad$ Priority of product $n$

$\mathrm{d}_{\mathrm{jt}} \quad$ Number of people aided in demand area $j$ at time $t$ (people)

$\mathrm{nc}_{\mathrm{ijmt}}$ Connectivity between facility $i$ and shelter $j$ by mode $m$ at period $t, \mathrm{nc}_{i j m t}=\{0,1\}$

$\operatorname{pd}_{\text {jnt }} \quad$ Demand of product type $n$ at demand point $j$ at period $t$ (product)

$\mathrm{td}_{\mathrm{j}} \quad$ Type of demand area $j$ served (shelter or neighborhood), $t d_{j}=\{0,1\}$

\section{Parameters of initial conditions}

$\mathrm{d}{ }_{\text {int }} \quad$ Initial inventory of product $n$ at supply facility $i$ at period $t$ (product) $\mathrm{f0}_{\text {iot }} \quad$ Initial personnel from organisation $o$ at supply facility $i$ at period $t$ (employee)

$\mathrm{h} 0_{\text {jot }} \quad$ Initial number of teams for healthcare from organisation $o$ at shelter $j$ at period $t$ (team)

$\mathrm{i}_{\mathrm{jnt}} \quad$ Initial inventory of product $n$ at demand point $j$ at period $t$ (product)

$\mathrm{r}_{\text {imot }}$ Initial staff available for distribution from organisation $o$ at supply facility $i$ at period $t$ (employee)

$s 0_{\text {jot }} \quad$ Initial personnel for shelter care from organisation $o$ at shelter $j$ at period $t$ (employee)

\section{Decision variables}

$\mathrm{AF}_{\text {iot }} \quad$ Increase of staff for operation of supply facility $i$ from organisation $o$ at period $t$ (employee)

$\mathrm{AH}_{\text {jot }}$ Increase of healthcare personnel in facility $j$ from organisation $o$ at period $t$ (team)

$\mathrm{AR}_{\text {imot }}$ Increase of distribution staff of mode $m$ in facility $i$ from organisation $o$ at period $t$ (employee)

AS $_{\text {jot }}$ Increase of shelter staff in facility $j$ from organisation $o$ at period $t$ (employee)

$\mathrm{BF}_{\text {iot }}$ Decrease of staff for operation of supply facility $i$ from organisation $o$ at period $t$ (employee)

$\mathrm{BH}_{\mathrm{jot}}$ Decrease of healthcare staff in facility $j$ from organisation $o$ at period $t$ (team)

$\mathrm{BR}_{\text {imot }}$ Decrease of distribution staff of mode $m$ in facility $i$ from organisation $o$ at period $t$ (employee)

BS $_{\text {jot }}$ Decrease of shelter staff in facility $j$ from organisation $o$ at period $t$ (employee)

$\mathrm{C}_{\text {inot }} \quad$ Products type $n$ from organisation $o$ sent to supply facility $i$ at period $t$ (product)

COST Total cost $(\$)$

$\mathrm{DS}_{\text {jnt }} \quad$ Unfulfilled demand of product $n$ at shelter $j$ at period $t$ (product)

$\mathrm{E}_{\mathrm{ijm} n \mathrm{t}} \quad$ Amount of relief type $n$ delivered from facility $i$ to shelter $j$ by mode $m$ at period $t$ (product)

$F_{\text {iot }} \quad$ Personnel from organisation $o$ allocated to supply facility $i$ at period $t$ (employee)

$\mathrm{G}_{\mathrm{ijm}} \quad$ Number of trips deployed from supply facility $i$ to shelter $j$ by mode $m$ at period $t$ (trips)

$\mathrm{H}_{\text {jot }} \quad$ Healthcare staff from organisation $o$ allocated to shelter $j$ at period $t$ (team)

$\mathrm{NH}_{\mathrm{jt}} \quad$ Expected number of people without healthcare at shelter $j$ at period $t$ (people)

$\mathrm{NS}_{\mathrm{jt}} \quad$ Expected number of people without shelter attention at shelter $j$ at period $t$ (people)

$\mathrm{P}_{\mathrm{jt}} \quad$ Number of people with relief shortages at demand point $j$ at period $t$ (people)

$\mathrm{PH}_{\mathrm{jt}} \quad$ Excess of people covered for healthcare at shelter $j$ at period $t$ (people)

$\mathrm{PS}_{\mathrm{jt}} \quad$ Excess of people covered for shelter attention at shelter $j$ at period $t$ (people)

$\mathrm{QF}_{\text {int }} \quad$ Number of products of type $n$ stored at supply facility $i$ at period $t$ (product)

$\mathrm{QS}_{\text {jnt }} \quad$ Number of products of type $n$ stored at demand point $j$ at period $t$ (product)

$\mathrm{R}_{\text {imot }}$ Transportation mode $m$ staff from organisation $o$ to be allocated at supply facility $i$ at period $t$ (employee)

$S_{\text {jot }} \quad$ Personnel from organisation $o$ allocated to shelter $j$ at period $t$ (employee)

$\mathrm{U}_{\text {imot }}$ Vehicles mode $m$ from organisation $o$ to be allocated at supply facility $i$ at period $t$ (vehicles)

UFR Total demand not fulfilled (people)

$\mathrm{W}_{\mathrm{ot}}$ Decision whether to activate organisation $o$ at period $t$ or not

$\mathrm{Y}_{\mathrm{jnt}} \quad$ Number of products of type $n$ consumed at demand point $j$ at period $t$ (product) 


\subsection{Model formulation}

The optimisation model balances the resources available during the whole disaster in order to choose which organisations to activate depending on the circumstances and the stage of the emergency. The multi-commodity multi-modal model is presented as follows:

$$
\begin{aligned}
\operatorname{MinCOST}= & \sum_{o} \sum_{t} W_{o t} * \sigma_{o t}+\sum_{i} \sum_{n} \sum_{o} \sum_{t} \varepsilon_{n} * C_{i n o t} \\
& +\sum_{i} \sum_{j} \sum_{m} \sum_{t} \varphi_{i j m} * G_{i j m t}
\end{aligned}
$$

$\operatorname{MinUFR}=\sum_{j} \sum_{t}\left(P_{j t}+N H_{j t}+N S_{j t}\right)$

Expression (1) minimises the cost of the organisations involved, the cost of procurement, and the cost of transportation across all organisations and all periods. Objective function (2) minimises the total unfulfillment of shelter care, healthcare, and relief distribution across all demand areas.

The constraints of the model are as follows:

$D S_{j n t}=p d_{j n t}-Y_{j n t} \quad \forall j, n, t$

Constraint (3) is used to calculate the unsatisfied demand of products at each period as the difference between the number of items required and the products consumed at each area.

$P_{j t}=\frac{\sum_{n} D S_{j n t} * b_{n} * p g_{n}}{\sum_{n} b_{n}} \quad \forall j, \mathrm{t}$

Equation (4) determines the unfulfillment level of each demand area based on the unsatisfied demand established by (3).

$Y_{j n t}+Y_{j n t+1}+Y_{j n t+2} \geq\left(p d_{j n t}+p d_{j n t+1}+p d_{j n t+2}\right) * \mu_{n} \quad \forall j, n, t$

Expression (5) is the equity constraint. It ensures that a minimum percentage of the demand is satisfied at each area over three adjacent periods. The effect of the constraint is to force the model to avoid solutions which focus on utilitarian measures alone. The purpose is to have a constant flow of products to all the demand zones.

$Q F_{\text {int }}=Q F_{\text {in }(t-1)}+\sum_{o} C_{\text {inot }}-\sum_{j} \sum_{m} E_{i j m n t}+d 0_{\text {int }} \quad \forall i, n, t$

Equation (6) determines the number of products available for shipment from the supply facility based on the inventory available from previous periods, the number of items that can be purchased in the period, and initial inventory available. Initial inventory can be used to incorporate leftover from previous decisions or consider one-off deliveries from external organisations not involved in ongoing operations.

$Q S_{j n t}=Q S_{j n(t-1)}+\sum_{i} \sum_{m} E_{i j m n t}-Y_{j n t}+i 0_{j n t} \quad \forall j, n, t$

Constraint (7) is used to establish the level of inventory at each demand area based on consumption, the items delivered, and the initial inventory available. Initial inventory can be used to incorporate leftover stock or extra support from external organisations.

$\sum_{i} C_{i n o t} \leq v_{n o t} * W_{o t} \quad \forall n, o, t$

Expression (8) ensures that items procured and delivered respect the maximum amount that can be purchased at each period by the organisations activated.

$a_{i} \geq \sum_{n} Q F_{\text {int }} * \phi_{n} \quad \forall i, t$

$s c_{j} * t d_{j} \geq \sum_{n} Q S_{j n t} * \phi_{n} \quad \forall j, t$

Constraints (9) and (10) restrict the volumetric storage capacity of supply facilities and demand areas, respectively. In equation (10), the type of facility is introduced. This provision was included to allow the system to serve shelters and/or directly distribute relief to affected neighbourhoods. If the facility is a shelter or a similar emergency facility, a value of 1 is introduced to allow relief storage and deploy staff for shelter care and healthcare. Otherwise, a value of 0 is used and the model can only deploy products without the possibility of storing them.

$\delta * a_{i} \leq \alpha * \sum_{o} F_{i o t} \quad \forall i, t$

Expression (11) ensures enough staff are allocated to supply facilities based on the size of the facility. A partial opening is allowed for small disasters or large buildings, though a minimum percentage of staff are required for operation $(\delta)$.

$d_{j t} * t d_{j} \leq \beta * \sum_{o} S_{j o t}+N S_{j t}-P S_{j t} \quad \forall j, t$

$d_{j t} * t d_{j} \leq \psi * \sum_{o} H_{j o t}+N H-P H_{j t} \quad \forall j, t$

Equations (12) and (13) determine the number of employees allocated to each facility for shelter attention and healthcare, respectively, as well as the shortage or excess of staff. The constraints estimate the number of people required based on the demand and the potential coverage of employees allocated. If the demand area served is an emergency facility managed by one of the participant organisations, healthcare and shelter care are deployed to the facility. Otherwise, only relief distribution is allowed.

$F_{i o t}=F_{i o(t-1)}+A F_{i o t}-B F_{i o t}+f 0_{i o t} \quad \forall i, o, t$

$S_{j o t}=S_{j o(t-1)}+A S_{j o t}-B S_{j o t}+s 0_{j o t} \quad \forall j, o, t$

$H_{j o t}=H_{j o(t-1)}+A H_{j o t}-B H_{j o t}+h 0_{j o t} \quad \forall j, o, t$

$R_{\text {imot }}=R_{\text {imo }(t-1)}+A R_{\text {imot }}-B R_{\text {imot }}+r 0_{\text {imot }} \quad \forall i, m, o, t$

Constraints (14), (15), (16), and (17) determine the variations in the number of personnel allocated to supply facility management, shelter care, healthcare, and distribution, respectively. Each equation considers the personnel allocated in the current period and its variation from the previous period. These equations have a term related to initial conditions because of personnel previously allocated to any facility. This can happen as a result of preparedness decisions (i.e. $t=0$ ), or because personnel are made available at a particular facility at a later period as a result of being transferred from other activities (e.g. cleaning debris and casualty transportation, among others). Therefore, these equations help keep track of the personnel available.

$\sum_{i} F_{i o t}=\eta_{o t} * W_{o t} \quad \forall o, t$

$\sum_{j} S_{j o t}=\theta_{o t} * W_{o t} \quad \forall o, t$

$\sum_{j} H_{i o t}=\kappa_{o t} * W_{o t} \quad \forall o, t$

$\sum_{i} \sum_{m} R_{\text {imot }} \leq \xi_{o t} * W_{o t} \quad \forall o, t$

Expressions (18), (19), (20), and (21) ensure that the number of people allocated per activity does not surpass the number of employees available per period from each one of the organisations activated.

$\lambda_{o t} * W_{o t} \geq \sum_{i} F_{\text {iot }}+\sum_{j} S_{\text {jot }}+\sum_{j} H_{\text {jot }}+\sum_{i} \sum_{m} R_{\text {imot }} \quad \forall o, t$

Equation (22) forces the number of operative resources used to be lower than the number of personnel available in the organisations deployed, including a term for healthcare teams if and only if one member is available for operative support. 
$\sum_{n} E_{i j m n t} * \Omega_{n} \leq t f_{m} * G_{i j m t} * n c_{i j m t} * \mathrm{cf}_{i j m} \quad \forall i, j, m, t$

Expression (23) determines the number of distribution trips from each supply facility to each demand area based on the number of items shipped and the capacity of the vehicles. Two relevant parameters are included in this expression: connectivity and coverage. Connectivity represents the existence of at least one usable path between supply facilities and demand areas. Through an assessment of the situation or the use of geographical information systems, a matrix of suitable paths per mode can be introduced. The existence of a path is represented with a value of 1 , otherwise 0 is introduced. Coverage is a term used to establish the maximum distance (or deployment time) between supply facilities and demand areas per mode. The distance matrix can be transformed into information regarding which demand areas can be effectively covered by each supply facility. If the demand area is within the distance (or time) set by the decision-maker, a value of 1 is introduced. Otherwise, a value of 0 is used.

$\sum_{j} G_{i j m t} \leq \zeta * \sum_{o} U_{i m o t} * \rho_{m} \quad \forall i, m, t$

Constraint (24) establishes the number of vehicles required to undertake the distribution trips. The number of trips is calculated considering the number of days available for distribution and the upper bound of trips that can be performed by day.

$U_{\text {imot }} \leq \frac{R_{\text {imot }}}{\gamma_{m}} \quad \forall i, m, o, t$

Equation (25) determines the number of employees needed for relief distribution based on the number of vehicles required and the number of staff deployed per vehicle.

$\sum_{i} U_{i m o t} \leq \tau_{m o t} * W_{o t} \quad \forall m, o, t$

Expression (26) ensures that the availability of vehicles by the participant organisations is respected.

$Q F_{i o t}, C_{i n o t}, Q S_{j n t}, G_{i j m t}, N H_{j t}, N S_{j t}, D S_{j n t}, P_{j t}, Y_{j n t}, E_{i j m n t}, F_{i o t}, S_{j o t}$,

$H_{j o t}, P S_{j t}, P H_{j t}$

$R_{\text {imot }}, A F_{\text {iot }}, B F_{\text {iot }}, A S_{\text {jot }}, B S_{\text {jot }}, A H_{\text {jot }}, B H_{\text {jot }}, A R_{\text {imot }}, B R_{\text {imot }}$,

$U_{\text {imot }} \in Z_{\geq 0}$

$W_{o t} \in\{0,1\}$

Finally, the declaration of integer and binary variables is presented.

\subsection{Model solution}

The result of a bi-objective model is a set of efficient solutions instead of a single value. Different methods were considered to find the solution. A lexicographic approach was discarded because of the number of objectives and the lack of hierarchy among them, whereas goal programming was not used because the thresholds can be biased by optimistic or pessimistic decision makers.

To find the Pareto frontier of the problem, two scalarization techniques were selected: the weighted-sum method and the $\varepsilon$-constraint method. The weighted-sum method is a traditional method to obtain the Pareto set. The $n$ number of objective functions are combined into a unique equation using a weighted sum of the functions. The weights are changed systematically to find the Pareto frontier. The function to optimise can be expressed as follows:

$g_{0}(x)=\sum_{i=1}^{k} p_{i} f_{i}(x)$

Where $p_{i}$ is the weighting factor and $f_{i}(x)$ the objective functions. To deal with the inability of the weighted-sum method to obtain the efficient set when the boundary is nonconvex, the $\varepsilon$-constraint method was also selected. In this method, one of the objective functions is optimised while the other is used as a constraint, changing the constraint value systematically. The general formulation for $n$ objective functions is presented in equations (28) and (29) as follows:

$\min / \max f_{i}(x) \quad \forall x \in X$

Subject to $f_{j}(x) \leq \varepsilon_{j} \quad \forall j=1,2, \ldots, n ; i \neq j$

\subsection{Model verification}

A hypothetical example was used to verify the model due to the absence of benchmark data in the literature. The model was solved in GAMS $^{\circ}$ using a random set of parameters. The result obtained using the weighted-sum method was equal to the solution expected. Analysis of the parameters and the effect of variations in the constraints were also undertaken.

Minimum satisfaction percentages across demand areas ranging from $10 \%$ to $100 \%$ were tested to analyse the equity constraint. Potential unfeasibility was identified in instances where the threshold was set too high. Additionally, setting high satisfaction percentages for every product notably increased solution time. Afterwards, different constraints were relaxed to identify dependencies among activities and the overall effect on the model. Parameter variability and extreme condition tests were also carried out to ensure that the model was not behaving in an absurd manner. The analysis showed that the model was operating within the expected boundaries.

\section{Application to disaster management in Mexico: the cases of Veracruz and Acapulco}

Mexico is a country commonly affected by disasters because of its geographical location between the Gulf of Mexico and the Pacific Ocean. The country has a disaster management system in place (SEGOB, 2006), but shortcomings identified recently endanger the significant portion of the population living under poverty conditions (World_Bank, 2013). The purpose of this section is to assess the applicability of the model to different regions of Mexico.

\subsection{Case studies}

Hurricanes are a significant problem in Mexico. Two coastal cities damaged in recent disasters were selected for analysis; one next to the Gulf of Mexico and the other next to the Pacific Ocean. Most of the damage caused by both hurricanes was because of flooding. The summary of both emergency situations can be seen in Table 1 . The flood level in both disasters was similar; however, the level of impact varied because of topography and demography.

Table 1

Case studies selected in Mexico.

\begin{tabular}{|c|c|c|}
\hline Year & $\begin{array}{l}\text { Location (City, } \\
\text { State) }\end{array}$ & Description \\
\hline 2010 & Veracruz, Veracruz & $\begin{array}{l}\text { Hurricane: Karl } \\
\text { Geographical location: Coastal city located next to } \\
\text { the Gulf of Mexico } \\
\text { Flood depth: } 1.5 \mathrm{~m} \\
\text { Start and end date: } 19 \text { th September } 2010-19 \text { th } \\
\text { October } 2010 \\
\text { Number of people sheltered: } 5140\end{array}$ \\
\hline 2013 & Acapulco, Guerrero & $\begin{array}{l}\text { Hurricane: Manuel } \\
\text { Geographical location: Coastal city located next to } \\
\text { the Pacific Ocean } \\
\text { Flood depth: } 1.5 \mathrm{~m} \\
\text { Start and end date: } 16 \text { th September } 2013-26 \text { th } \\
\text { November } 2013 \\
\text { Number of people sheltered: } 13,062\end{array}$ \\
\hline
\end{tabular}


The reason two cases were introduced was because of the difference in the level of impact and also to provide solid support for the conclusions. Even with similar flood depths, the impact of the events and the activities performed were different. Veracruz is used as an example of a small-scale disaster with a limited number of facilities used, the participation of governmental agencies only, and with emergency operations lasting for less than a month. This disaster had a demand profile with peaks at the beginning and the middle of the emergency. Acapulco, meanwhile, is used as an example of a medium-scale disaster. The situation there led to several facilities having to be opened, the participation of governmental organisations along with the Red Cross, and ongoing operations for nearly seven weeks. The demand profile in this case peaked in the first stage and decreased over time. Therefore, the cases tested the model under different settings from which conclusions could be drawn.

The conditions presented in the table were used to analyse both floods using Geographical Information Systems (GIS). The reason GIS was used for this research was because it has several potential contributions to different disaster management phases (Ozdamar and Ertem, 2015). These systems allow the user to analyse the geographical conditions of the event and display results graphically (Lee et al., 2011). That is why many organisations, including the United Nations, have GIS units (Kaiser et al., 2003). This research used a combination of raster and vector GIS for the analysis of the situation. TransCAD ${ }^{\circ}$ was the vector GIS introduced to locate potential facilities and to perform network analysis using maps of the areas. Next, the procedure described by Rodríguez-Espíndola et al. (2016) was undertaken to create flood maps in the raster software IDRISI ${ }^{\circ}$. A macro was designed to introduce the flood depth and determine the impact of the flood. The maps were validated through comparison to flood masks developed by the Navy (SEMAR) and the National Centre for Disaster Prevention. Using map algebra, the flood maps were used to identify safe facilities and the level of damage on the demand areas. The percentage of damage on each area and the impact in the road network were used to introduce the conditions of the flood to the model through the disaster-specific parameters. The purpose was to use realistic data.

\subsubsection{The case of Veracruz, Mexico}

Veracruz is located around $90 \mathrm{~km}$ away from the capital of the State and has an altitude of $10 \mathrm{~m}$ above sea level (INEGI, 2010). Fig. 2 depicts the image of Veracruz-Boca del Río, which is on the East side of the country (Google_Earth, 2016). Veracruz is a relevant case because it is the most important commercial port in Mexico and manages approximately $30 \%$ of the maritime trade in the country (CAAAAREM, 2009).

In 2010, Hurricane Karl reached peak intensity with very high winds, causing 10-15 inches of rainfall in half of the State of Veracruz which resulted in severe floods. Water levels reached heights of up to $1.5 \mathrm{~m}$ in some areas, including the city of Veracruz (AFP, 2010).

\subsubsection{The case of Acapulco, Mexico}

The city of Acapulco is located in the State of Guerrero in the west side of Mexico. Fig. 3 depicts the city and its surrounding region (Google_Earth, 2016). The city is one of the most important touristic attractions in the country, as shown by the 4,890,456 tourists that visited the region in 2010 alone (INEGI, 2010).

Hurricane Manuel caused around 44,216 people to require shelter in the State of Guerrero (García et al., 2015) and the estimated value of the damage caused by the emergency was approximately 23,441 million pesos (US\$ 1.813 billion). The city of Acapulco was one of the most affected communities in the State of Guerrero. During the emergency, the city experienced a flood that reached a height of approximately $1.5 \mathrm{~m}$ (EOS, 2013).

\subsection{Data collection}

Governmental organisations involved in logistics operations for hydro meteorological disasters in Mexico were identified and enquired about the situation in both cases. In Veracruz, nine operational agencies confirmed having primary participants on the field. The participating agencies were: food services (DICONSA), DIF, Social Security Mexican Institute (IMSS), civil protection authorities (PC), National Health Ministry (SMEXICO), State Health Ministry of Veracruz (SVERACRUZ), the military (SEDENA), Ministry of Interior (SEGOB), and SEMAR. On the other hand, ten governmental organisations declared their participation in relief activities during the emergency in Acapulco. These included nine governmental agencies and the Mexican Red Cross. Information was gathered from SMEXICO, the Health Secretariat of the State (SGUERRERO), IMSS, DICONSA, SEDESOL, DIF, SEDENA, SEMAR, civil protection authorities (SSPPC), and the website of the Red Cross. The details of each organisation are listed in Table 2.

Parameters related to the decision maker were obtained from regulations and expert opinion from authorities. Information from the agencies was obtained using freedom of information requests filed with the Mexican transparency information system and the website of the Mexican Red Cross. Disaster-specific parameters were determined based on information from authorities and a flood analysis in a GIS. The analysis in the GIS included the creation of flood maps to assess the situation and provide information for the model based on the process explained by Rodríguez-Espíndola et al. (2016).

From the products listed in the Appendix IV of the Natural Disaster Fund (FONDEN), five items periodically replenished were included for analysis: food kits, medical kits, cleaning kits (ckit), personal kits (pkit), and a 'hygiene kit' (hkit). The latter contains diapers and feminine hygiene towels. Both cases consider periods of four days because the relief in the country is provided in packages for four people for four days. Additionally, that timeframe allows processing item requests made to FONDEN. Priority in both instances was set as a value of 5 for food and medicine, and a value of 1 for the rest of the items. The values of several other parameters are presented on compacted tables in the Appendix. For information about the remaining tables, please contact the corresponding author.

\subsection{Model solution}

The real conditions of both disasters were included in scenarios with a flood of $1.5 \mathrm{~m}$. To test the model under different circumstances in both cases, one scenario with a flood level of $0.5 \mathrm{~m}$ and another one with a water depth of $2.5 \mathrm{~m}$ were introduced for each to consider a better and worse situation, respectively. The purpose was to identify if authorities had enough capacity to deal with different conditions in both settings.

The weighed-sum method and the $\varepsilon$-constraint method were applied on GAMS $^{\circ}$ using CPLEX $^{\oplus}$ as solver on 150 iterations for each one of the scenarios, with a time limit of $600 \mathrm{~s}$ and a relative gap set to zero. All the instances were run on a laptop with an Intel core i7 processor and $8 \mathrm{~GB}$ of RAM. The weighted-sum method was used with 150 combinations of weights among the objectives ranging from 0 to 1 , which were normalised using the ideal values of minimising each individual objective. For the $\varepsilon$-constraint method, the objective was to minimise unfulfillment and the cost function was used as a constraint with 150 values, which varied from the minimum to maximum cost obtained from its individual minimisation.

\subsubsection{Model solution and analysis of the flood in Veracruz}

A total of 100, 142, and 160 non-dominated points were obtained for the scenarios with a flood depth of $0.5 \mathrm{~m}, 1.5 \mathrm{~m}$, and $2.5 \mathrm{~m}$, respectively. The resulting Pareto frontiers are shown in Fig. 4.

The variations among scenarios are caused by the differences in demand, which in turn affected cost. Each one of the points presented in the graph represents a different policy, meaning a different combination of decisions that can be employed by the decision maker. The selection of the policy should come from the preferences of the decision- 


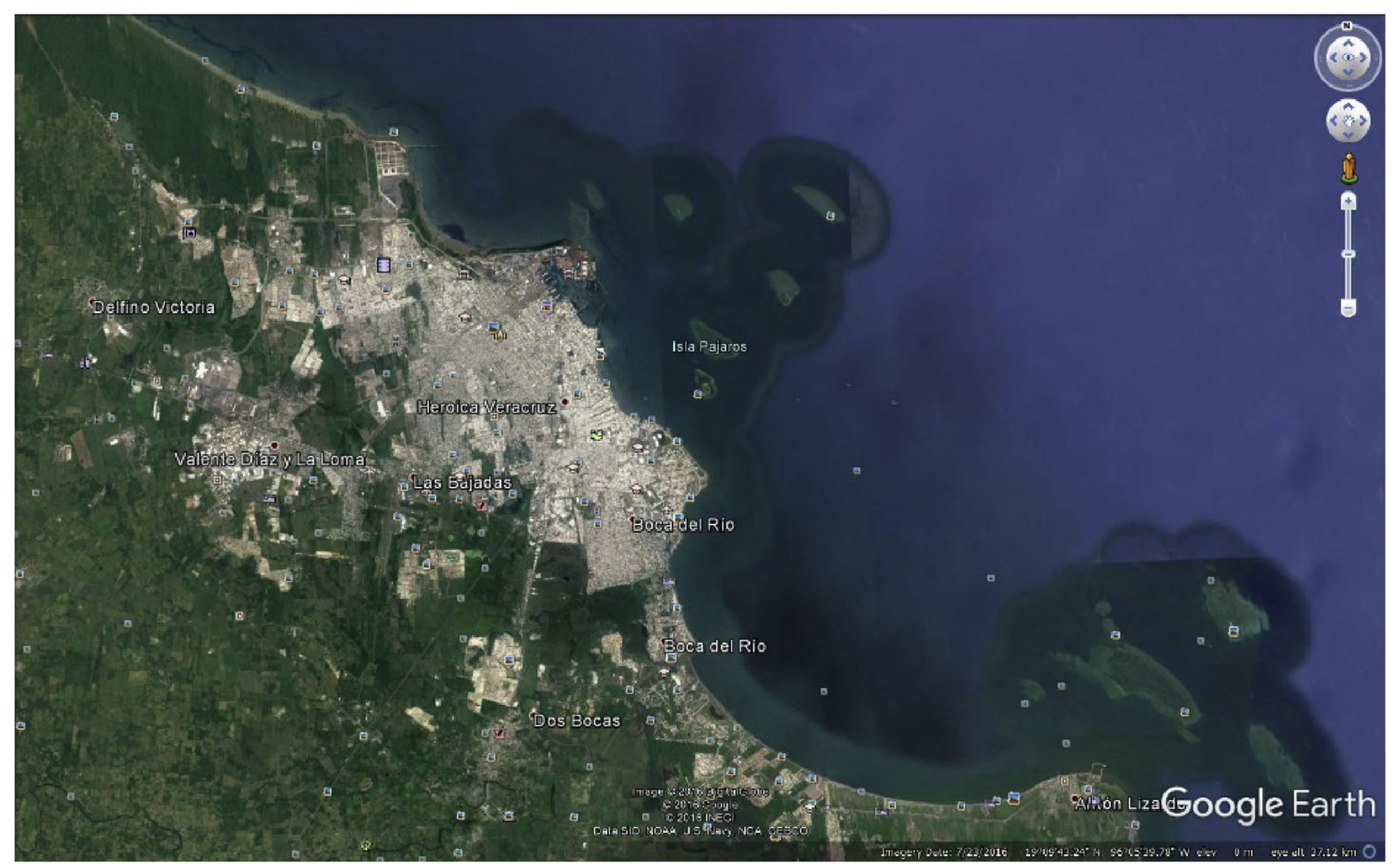

Fig. 2. Region Veracruz-Boca del Río.

Source: Google_Earth (2016).

maker.

The model demonstrates the capabilities for handling dynamic conditions. For instance, Fig. 5 shows the number of organisations activated in the different solutions for the flood depth of $1.5 \mathrm{~m}$. There was a peak in demand at the beginning and at the middle of the emergency, which was addressed by the model by activating more agencies at these stages. The model determined the number of organisations involved at each period, based on their size and resources.

Table 3 provides an overview of the results obtained per scenario. The table shows the minimum and maximum cost incurred in each one of the Pareto frontiers, the maximum number of organisations simultaneously participating at any period, the maximum fill rate of products obtained, and the maximum fill rate of shelter (NS) and medical $(\mathrm{NH})$ achieved. Authorities had enough resources to satisfy the requirements of the victims in the three scenarios.

This result shows that the disaster management system in Mexico has the potential to successfully handle different instances. However, the management of the organisations can be improved. Even considering a case with higher demand than the real emergency, fewer organisations than the participating agencies were required. This result highlights the importance of managing the number of participating organisations to reduce cost and avoid convergence.

\subsubsection{Model solution and analysis of the flood in Acapulco}

The resulting Pareto frontier of each scenario is presented in Fig. 6. The results demonstrate that authorities had enough capacity and resources to handle the three instances in Acapulco.

The demand in Acapulco was sudden and peaked at the first stage, decreasing slowly over time. Fig. 7 illustrates the number of organisations deployed in the instance of the flood of $1.5 \mathrm{~m}$. The model deployed organisations based on their size, the situation, and the demand pattern. In this case, the number of organisations activated was constant over time, with larger organisations being eventually replaced by smaller organisations towards the middle of the emergency.

Table 4 offers an overview of the results of the three scenarios. The results demonstrate the need for fewer organisations than the number of participating agencies that were deployed in reality, even for a scenario with higher demand than the real instance. This result is consistent with the findings from the first case study and questions the efficiency in the use of resources. In both cases, the model was able to increase and decrease the number of organisations required at every scenario depending on the scale of the event and the period. The results highlight the potential of the model to keep only necessary resources in the field.

\section{Evaluation of the model}

Most of the articles focused on relief distribution assume a single organisation. The implications of that approach are that either each participant acts independently, or resources are aggregated, leaving allocation to be decided by other means. This research analyses the two possibilities using real information. The first instance considers the independent participation of all the organisations involved, whereas the second reconstructs the real decisions taken by Mexican authorities, assuming coordination among participants. In this section, all the instances compared consider floods of $1.5 \mathrm{~m}$ in both Veracruz and Acapulco.

\subsection{Scenario with independent participation of each organisation}

This part assumes that each organisation would be solving an optimisation model individually to identify their optimal combination of 


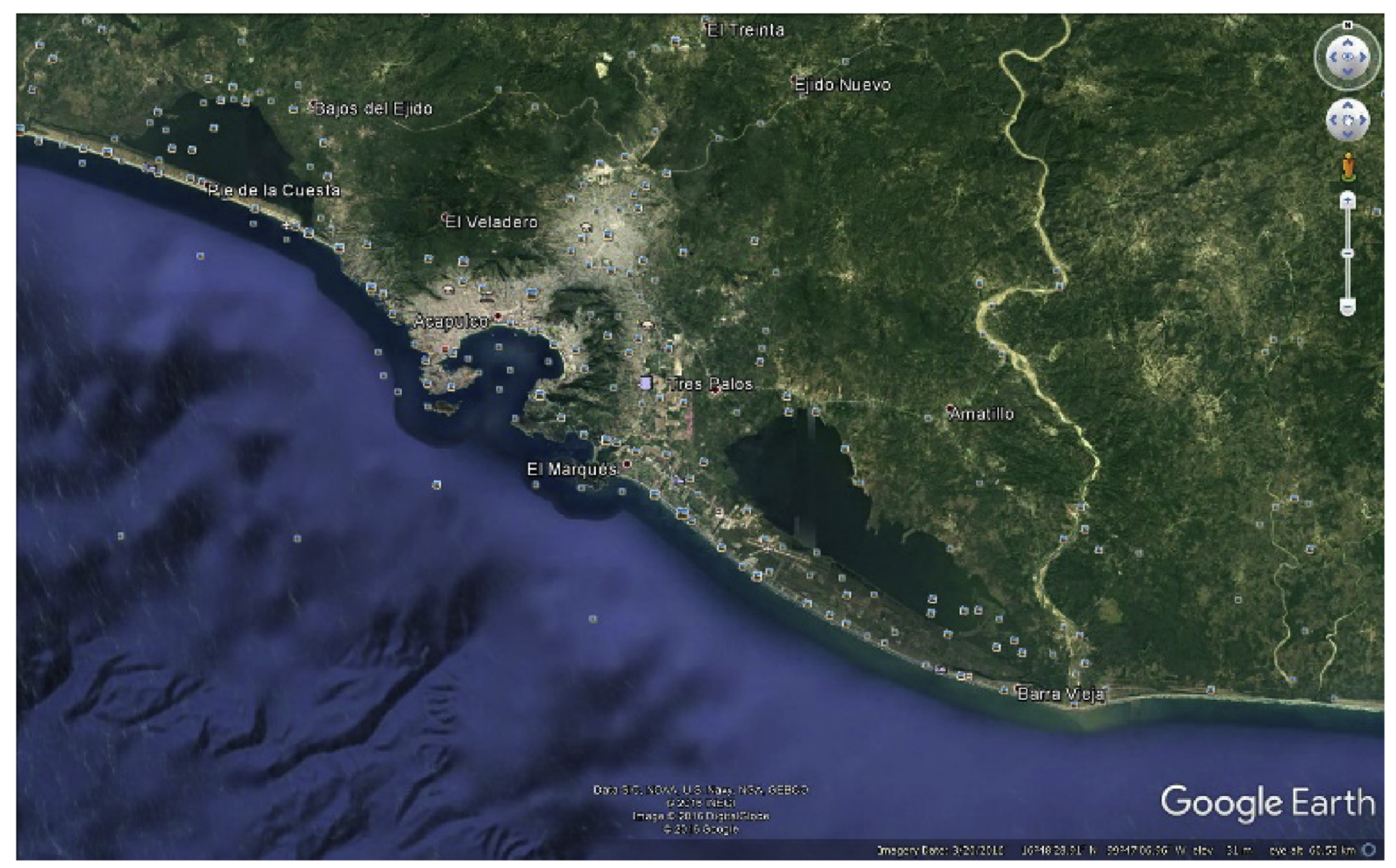

Fig. 3. Acapulco, Guerrero.

Source: Google_Earth (2016).

Table 2

Organisations involved in disaster management in the floods of Veracruz and Acapulco.

\begin{tabular}{|c|c|c|c|}
\hline Case & Organisation & Activities & Further information \\
\hline Both & DICONSA & $\begin{array}{l}\text { Management of social programmes, and in charge of the supply of food and supplementary items that } \\
\text { can be requested in disasters. }\end{array}$ & https://www.gob.mx/diconsa \\
\hline Both & DIF & $\begin{array}{l}\text { Running public programmes to enhance family integration. It provides food and support in shelters } \\
\text { during disasters. }\end{array}$ & https://www.gob.mx/difnacional \\
\hline Both & IMSS & $\begin{array}{l}\text { Assistance related to public health and social security. In disasters it provides medical products and } \\
\text { expertise. }\end{array}$ & http://www.imss.gob.mx/ \\
\hline Both & SMEXICO & $\begin{array}{l}\text { Coordination of health services in Mexico. During disasters it provides medical products and } \\
\text { expertise. }\end{array}$ & https://www.gob.mx/salud/ \\
\hline Both & SEMAR & $\begin{array}{l}\text { Management of the navy force of the country. It is a large organisation with significant human } \\
\text { resources and vehicles, which are deployed during disasters. }\end{array}$ & https://www.gob.mx/semar \\
\hline Both & SEDENA & $\begin{array}{l}\text { Military control in Mexico. It possesses significant human resources and vehicles which are deployed } \\
\text { during disasters. }\end{array}$ & https://www.gob.mx/sedena \\
\hline Veracruz & SVERACRUZ & Healthcare at State level in Veracruz. In disasters it provides medical products and expertise. & https://www.ssaver.gob.mx/ \\
\hline Veracruz & $\mathrm{PC}$ & $\begin{array}{l}\text { Civil protection at the State level in Veracruz. It liaises with SINAPROC and provides human resources } \\
\text { in the field }\end{array}$ & $\begin{array}{l}\text { http://www.veracruz.gob.mx/ } \\
\text { proteccioncivil/ }\end{array}$ \\
\hline Veracruz & SEGOB & $\begin{array}{l}\text { Liaises with the three branches of government and oversees the SINAPROC. During disasters it liaises } \\
\text { with agents on the field, handles requests and provides limited resources }\end{array}$ & https://www.gob.mx/segob \\
\hline Acapulco & SGUERRERO & Healthcare at State level in Guerrero. In disasters it provides medical products and expertise. & $\begin{array}{l}\text { http://guerrero.gob.mx/dependencias/ } \\
\text { secretaria-de-salud/ }\end{array}$ \\
\hline Acapulco & SEDESOL & $\begin{array}{l}\text { Management of social development programmes in Mexico. In disasters it provides some products, } \\
\text { vehicles and employees }\end{array}$ & https://www.gob.mx/sedesol \\
\hline Acapulco & SSPPC & $\begin{array}{l}\text { Civil protection at the State level in Guerrero. It liaises with SINAPROC and provides human resources } \\
\text { in the field }\end{array}$ & www.seguridadgro.gob.mx/inicio/ \\
\hline Acapulco & RED CROSS & $\begin{array}{l}\text { Support for community resilience with strong component of support during disasters. Provides food, } \\
\text { vehicles and volunteers. }\end{array}$ & $\begin{array}{l}\text { https://www.cruzrojamexicana.org.mx/ } \\
\text { servicios }\end{array}$ \\
\hline
\end{tabular}

activities. In this context, organisations are aware of the presence of other actors in the field, but they prefer to act based on their own information. For this scenario to be feasible, the organisations must operate throughout all periods to support the demand areas of their choosing. As occurred in reality, more than one organisation could be providing support at the same facility at the same time. The rest of the information is equal to the scenarios of $1.5 \mathrm{~m}$ presented in the previous section, with the difference being that the model is solved for each organisation independently.

Equity was a challenge in this scenario. Constraint (5) proved 


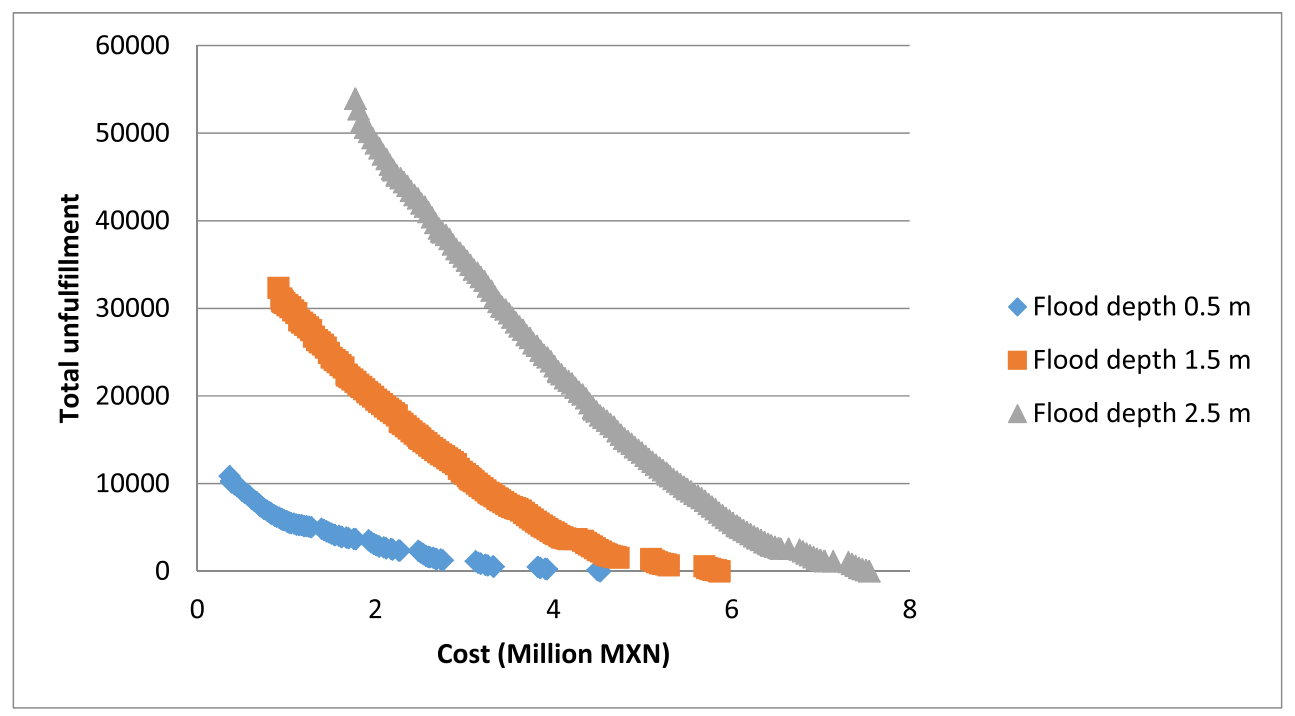

Fig. 4. Pareto frontier of the three scenarios in the region of Veracruz-Boca del Río.

unrealistic for a single organisation, causing unfeasibility. This was because each organisation has limited material resources, which prevents them from satisfying the constraint. Therefore, this constraint was not employed for the agencies. Hence, for comparability, a scenario using the model proposed without the equity constraint was solved.

Assuming agencies would focus on the level of service, the model only minimised unfulfillment. Fig. 8(a) and (b) illustrate the results for the cases of Veracruz and Acapulco, respectively. Each figure shows the comparison between the Pareto frontiers obtained by the model (original response), the models relaxing the equity constraint (no equity response), and the most service-oriented solution for each one of the agencies (acronym of the agencies). The results of the agencies listed show the minimum level of unfulfillment achieved by them acting independently with their own resources alone in comparison to a coordinated response.

The economic impact of having an excess of resources can be seen in both cases. SVERACRUZ and SGUERRERO are organisations with a large number of human resources (See Appendix) and expensive medical teams available in Veracruz and Acapulco, respectively. Each one of these organisations had more than enough medical personnel to satisfy the needs of the emergency, but they lacked resources for other activities. Organisations such as DIF, SEDENA, and SEMAR had a more balanced response, but they lacked the specialist expertise of other organisations.

The cases demonstrate that ignoring the interdependence between organisations can result in sub-optimal solutions, even using optimisation models. The comparison of the performance of individual agencies with the performance of the coordinated response shows a high level of unfulfillment and excessive cost. None of the organisations involved in the flood could have handled the emergency on their own. The reason for this is the absence of resources for providing both products and services at most organisations, which highlights the

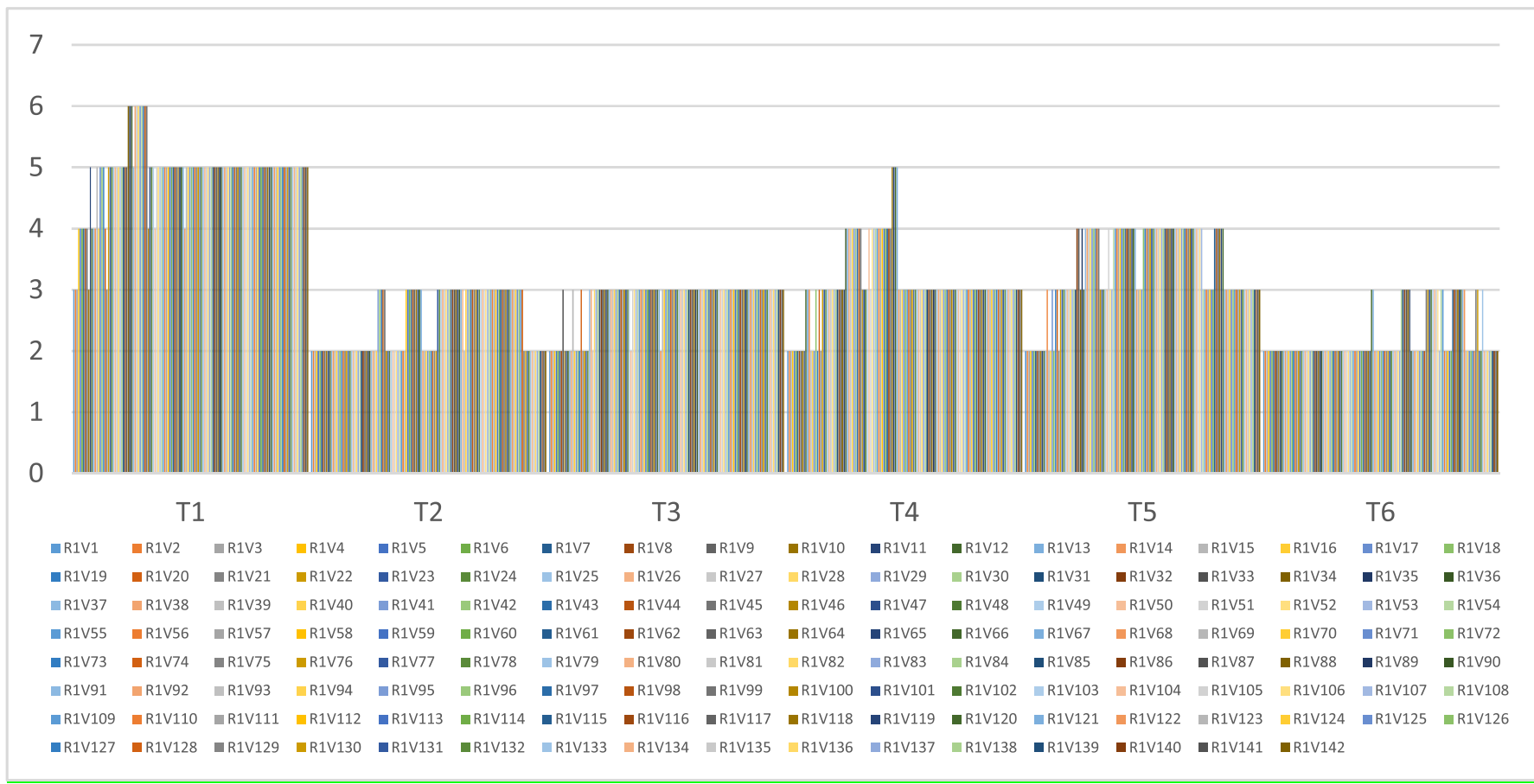

Fig. 5. Number of organisations deployed per period in the scenario of $1.5 \mathrm{~m}$ flood in Veracruz. 
Table 3

Performance measures of the results obtained for the three scenarios in Veracruz-Boca del Río.

\begin{tabular}{|c|c|c|c|c|c|c|c|c|c|c|}
\hline \multirow[t]{2}{*}{ Flood depth (m) } & \multirow{2}{*}{$\begin{array}{l}\text { Cost (MXN) } \\
\text { Min }\end{array}$} & \multirow[b]{2}{*}{ Max } & \multirow[t]{2}{*}{ Maximum organisations $\mathrm{p} /$ period } & \multicolumn{7}{|c|}{ Maximum Fill Rate (\%) } \\
\hline & & & & Food & Med & Ckit & Pkit & Hkit & $\mathrm{NH}$ & NS \\
\hline 0.5 & 362,263 & $4,522,990$ & 5 & 100 & 100 & 100 & 100 & 100 & 100 & 100 \\
\hline 1.5 & 910,665 & $5,864,065$ & 6 & 100 & 100 & 100 & 100 & 100 & 100 & 100 \\
\hline 2.5 & $1,774,800$ & $7,542,852$ & 6 & 100 & 100 & 100 & 100 & 100 & 100 & 100 \\
\hline
\end{tabular}

importance of interoperability among organisations to complement and support each other.

The effect of the equity constraint can be seen on low-cost solutions in both cases, where the results of the original model and the model relaxing the equity constraint vary. The reason for the difference in these results is because equation (5) makes several cost-effective solutions unfeasible. The constraint forces the model to find alternatives to serve all demand areas, disregarding size or location, which can render several cost-efficient solutions unfeasible.

\subsection{Scenario based on the real activities performed by authorities}

The second part of the experimentation includes a comparison between the results from the model and the actual decisions made by authorities. To perform the comparison, an instance including information about the decisions made by authorities was created for the case of Veracruz and another was prepared for the case of Acapulco. Most of the parameters related to the decision-maker, organisations, initial conditions, and the context of the disaster were directly obtained from authorities. The decisions gathered from the data that were included exclusively in the real instances included facilities actually used during the event, amount of relief shipped, number of personnel employed per activity, the upper bound of products available for purchasing, number and type of vehicles deployed, and demand per facility. Data regarding the number of non-medical and medical items delivered per period per city were provided by the Ministry of Interior. The information was corroborated with data publicly available from FONDEN. Perfect coverage, perfect connectivity, and the absence of the equity constraint were incorporated into the reconstructed scenarios to avoid unfeasibility.

In cases where data about resources was available for a single period, the information was assumed to be constant for every interval. This assumption was considered sensible because, in the current system, all resources should be available for deployment at different periods. As decisions related to the allocation of resources were not recorded by authorities, these decisions were optimised to obtain the best possible outcome of the decisions made by them.

The ideal points of both performance measures for the scenarios are listed in Table 5. There is a small variation of cost between the solution of the individual minimisation of cost and the individual minimisation of unfulfillment in both instances. This is because most of the decisions were obtained from the information given by authorities. As the organisations involved and the amount of relief delivered during both disasters were recorded by them, only the transportation cost was optimised. Based on that variation of cost and focusing on providing the best possible care for the victims, the solution with the highest fill rate in both cases was used for comparison.

The representation of the best possible outcome of the decisions taken by authorities in Veracruz and Acapulco are compared to the Pareto frontiers obtained from the model in Fig. 9(a) and (b), respectively. In both cases, there was a significant overflow of food and human resources, which led to a considerable difference in terms of cost. Conversely, not enough hygiene kits were sent to the areas, which led to a delay in the delivery of medical kits.

The results illustrate that interoperability in the real activities was essential to reduce the level of unfulfillment in comparison to the cases of independent agencies. FONDEN was able to supply products and use human resources from organisations such as SEDENA and SEMAR for distribution. Healthcare organisations had enough resources in the field and operative support for shelters was provided by different organisations. In fact, the graphs show that considerably more resources than necessary were used in both instances. This was reflected in cost, which was extremely high in comparison to the results of the model.

The reader could be concerned about an overestimation of cost given the assumption of uninterrupted presence. Nevertheless, cost was increased greatly by the amount of relief sent to the area, representing nearly $70 \%$ of the overall expenditure in Veracruz and $34 \%$ of the overall cost in Acapulco. In both cases, only the cost of the relief sent to

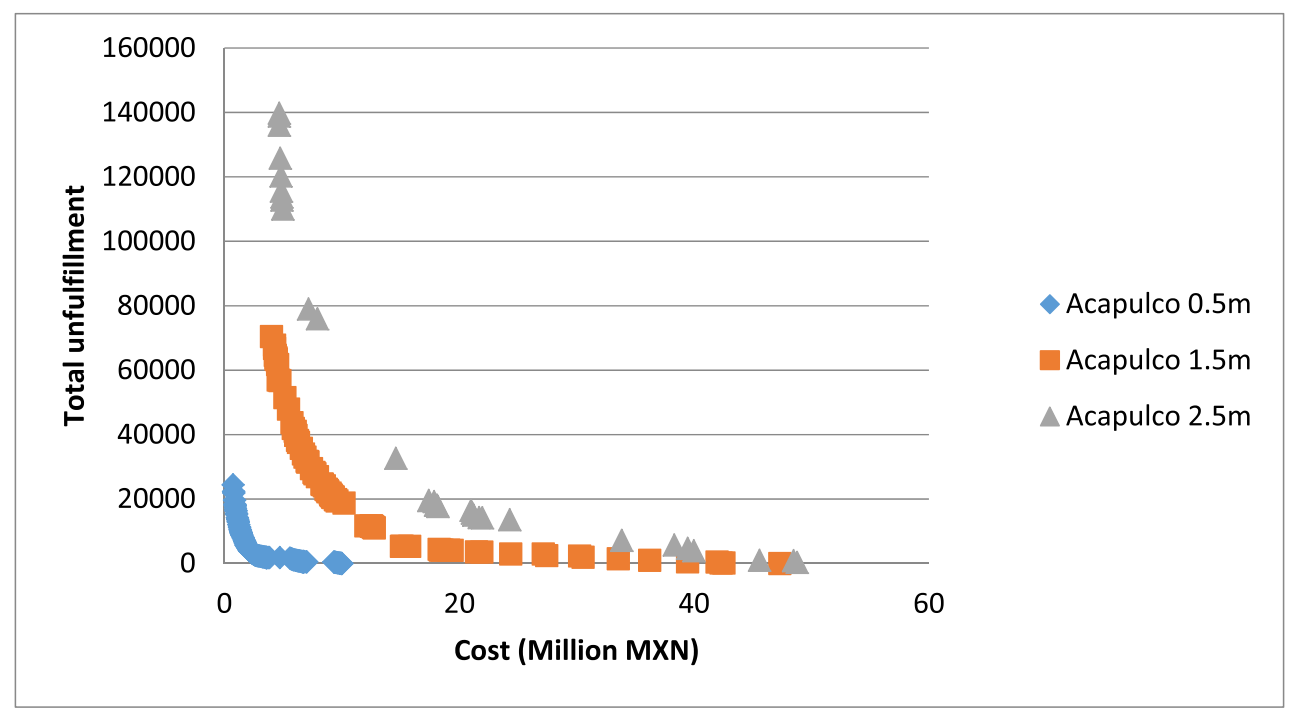

Fig. 6. Pareto frontier of the three scenarios in Acapulco. 


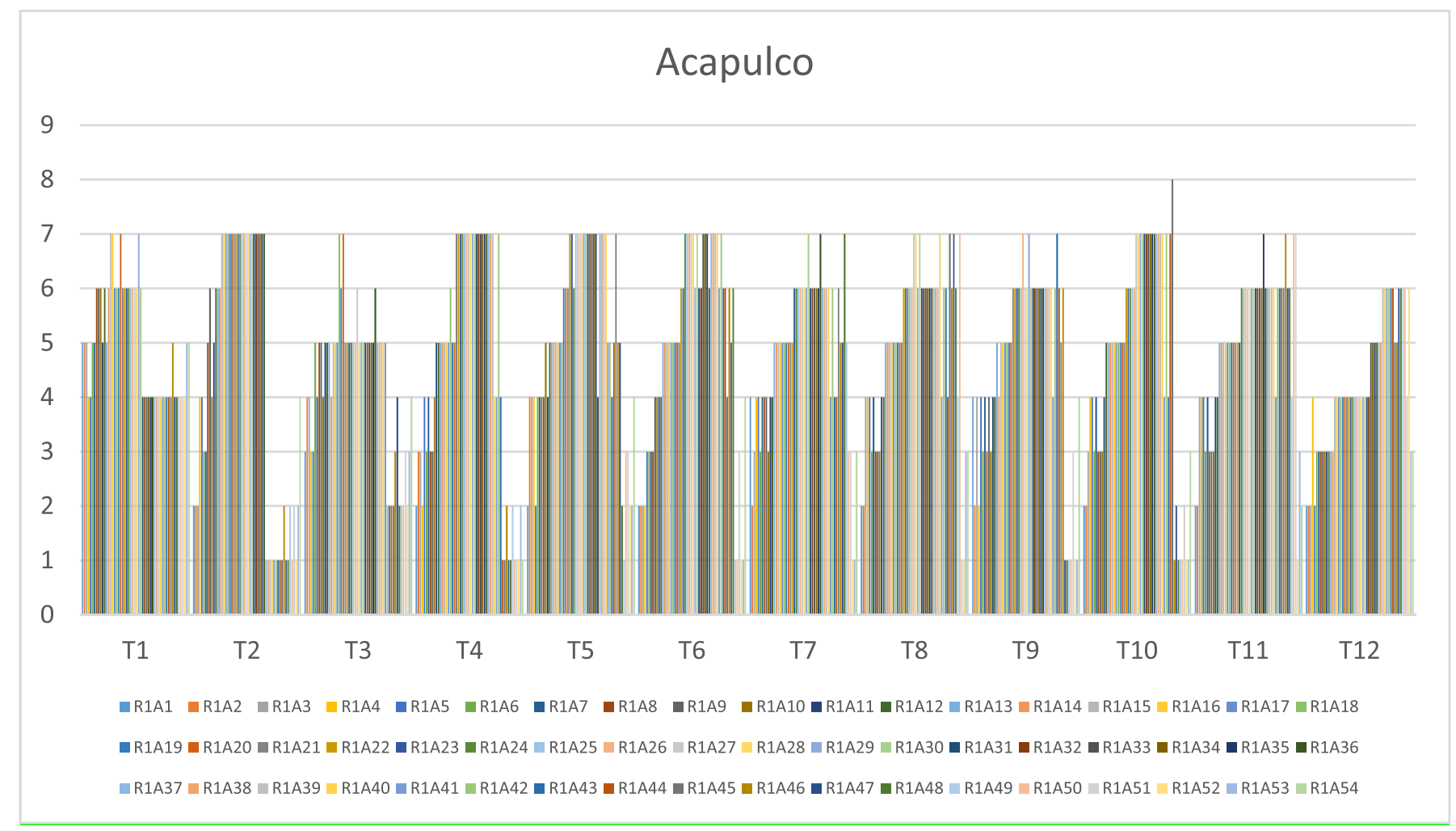

Fig. 7. Organisations deployed by the model in the flood of $1.5 \mathrm{~m}$ in Acapulco.

Table 4

Performance measures of the results obtained for the three scenarios in Acapulco.

\begin{tabular}{|c|c|c|c|c|c|c|c|c|c|c|}
\hline Flood depth (m) & \multicolumn{2}{|c|}{ Cost (MXN) } & Maximum organisations $\mathrm{p} /$ period & \multicolumn{7}{|c|}{ Maximum Fill Rate (\%) } \\
\hline 0.5 & 728,638 & $9,998,733$ & 6 & 100 & 100 & 100 & 100 & 100 & 100 & 100 \\
\hline 2.5 & $4,658,644$ & $48,777,316$ & 7 & 100 & 100 & 100 & 100 & 97.3 & 100 & 100 \\
\hline
\end{tabular}

the area would be enough to provide a higher fill rate using the optimisation model proposed rather than the one achieved in reality. These scenarios show the capability of authorities to provide products and services to all the victims. However, that potential was not reflected in reality. The comparison depicts the advantages of the optimisation model solution over the current approach.

\subsection{Analysis of results}

Table 6 provides a comparison of four different solutions for the cases of Acapulco and Veracruz for the floods of $1.5 \mathrm{~m}$. The values presented for each case represent the maximum level of service from agencies working independently (Agencies), the maximum level of service from real activities (Real), the maximum level of service from the response model (MFR), and the solution chosen by the authors of this work operating as decision-makers (R1V114/R1A46). For comparability, the scenarios of the agencies were created from the combined results of all of the organisations acting independently on each disaster. To assess the performance of the model, the table provides a summary of all the experiments presented in the articles.

The solution chosen by the authors of this work operating as decision-makers was obtained through several iterations, using an interactive approach (see Miettinen et al., 2008). The principal author selected a solution based on his preferences and that solution was discussed among the other members of the team. If the solution was not acceptable from the perspective of any member, another solution was chosen until the team reached an agreement. The purpose of the solution is to show the value of the trade-off between objectives and its impact.

The analysis presented demonstrates the resource underutilization created by the proactive approaches (Chakravarty, 2011) currently used by authorities. Fewer organisations were required to manage both situations, which contradicts the common practice of sending every available agency to the field. The ability to decide which institutions are required instead of sending every potential participant to the affected area can boost the efficient use of resources and improve operations. Only the optimisation model achieved a $100 \%$ fill rate across products and services on each case, with considerably lower cost than real activities and independent decision-making. The instance with independent agencies suffered from overlaps and duplication of efforts in some areas, preventing organisations from using the resources efficiently. This clearly states the potential value of collaboration among participants.

In both cases, authorities were able to purchase enough products to meet the requirements. However, the immediate response seems to have been delayed because of the length of the process required to request relief. Additionally, there were inconsistencies in the decisions about the type and number of items required, as shown by the variations in the number of the diapers and female hygiene towels delivered from one case to the other. The importance of the trade-off between 

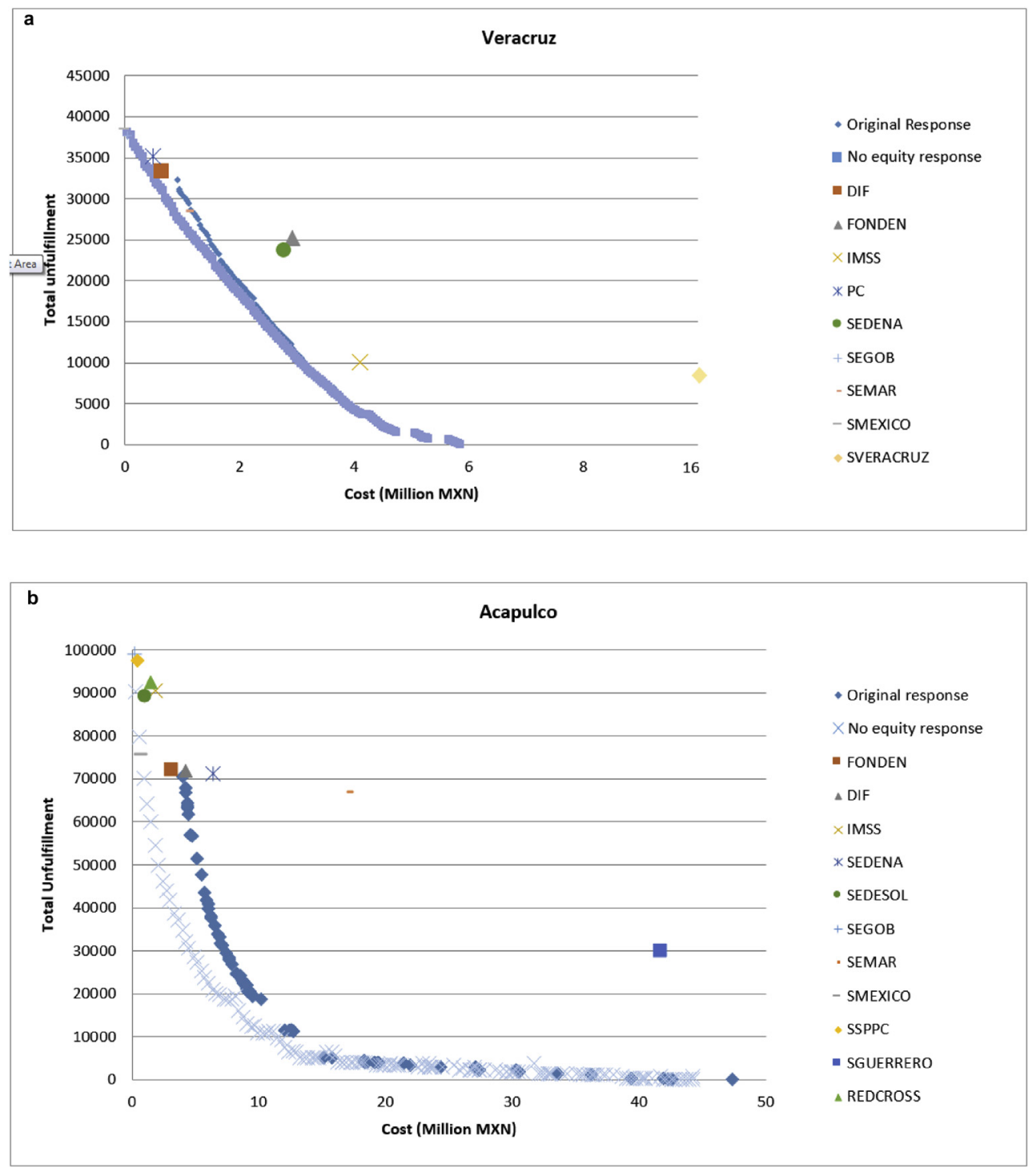

Fig. 8. (a). Comparison of the results for individual agencies in the case of Veracruz. (b). Comparison of the results for individual agencies in the case of Acapulco.

Table 5

Ideal points for each one of the cases under real circumstances in Veracruz and Acapulco.

\begin{tabular}{lllll}
\hline Objective & Veracruz & \multicolumn{3}{c}{ Acapulco } \\
\cline { 2 - 5 } & Cost (MXN) & $\begin{array}{l}\text { Total } \\
\text { unfulfillment }\end{array}$ & Cost (MXN) & $\begin{array}{l}\text { Total } \\
\text { unfulfillment }\end{array}$ \\
\hline $\begin{array}{c}\text { Minimise cost } \\
\begin{array}{c}\text { Minimise } \\
\text { unfulfillment }\end{array}\end{array}$ & $81,552,000$ & 38,570 & $114,350,000$ & 101,990 \\
& $81,575,576$ & 4490 & $114,530,000$ & 5800 \\
\hline
\end{tabular}

performance measures and the impact of the dynamic approach can be observed in Table 5. For instance, between R1A46 and MFR in Acapulco, an improvement of less than $10 \%$ of healthcare coverage has an impact of over 21 million MXN. This is because, at some periods, the system used the maximum number of healthcare employees (first stages), later withdrawing the largest healthcare agency (SMEXICO) and balancing resources using the two remaining organisations (SGUERRERO and IMSS). Conversely, the case of Veracruz shows that an investment of a little over 1.6 Million MXP would improve healthcare coverage on nearly $25 \%$. This highlights the value of balancing two performance measures to allow the decision-maker to consider trade- offs. This becomes more important for medium-scale and large-scale situations, in which the variations among solutions can become significant.

The number of organisations and resources deployed per stage delivered by the model were consistently lower than accounts from reality. The model considered the size and resources of each one of the organisations to deploy the optimal number of them to the field based on the existing conditions. Overall, the model provided logistics solutions whilst managing the required units in the field at different time periods, with the advantage of preventing overlaps among organisations. The result was a significant reduction of cost and a more effective spread of resources across time for the entire emergency.

\section{Conclusions}

This paper proposes the first dynamic response model for resource allocation and relief distribution that also considers the optimisation of the number of organisations involved. The application of the model to two major floods in Mexico has shown its potential to balance cost and level of service while at the same time efficiently managing the number of organisations with considerations of equity. This research contributes to a wider body of research that emphasises the importance of coordination. The analysis presented here demonstrates the importance of 

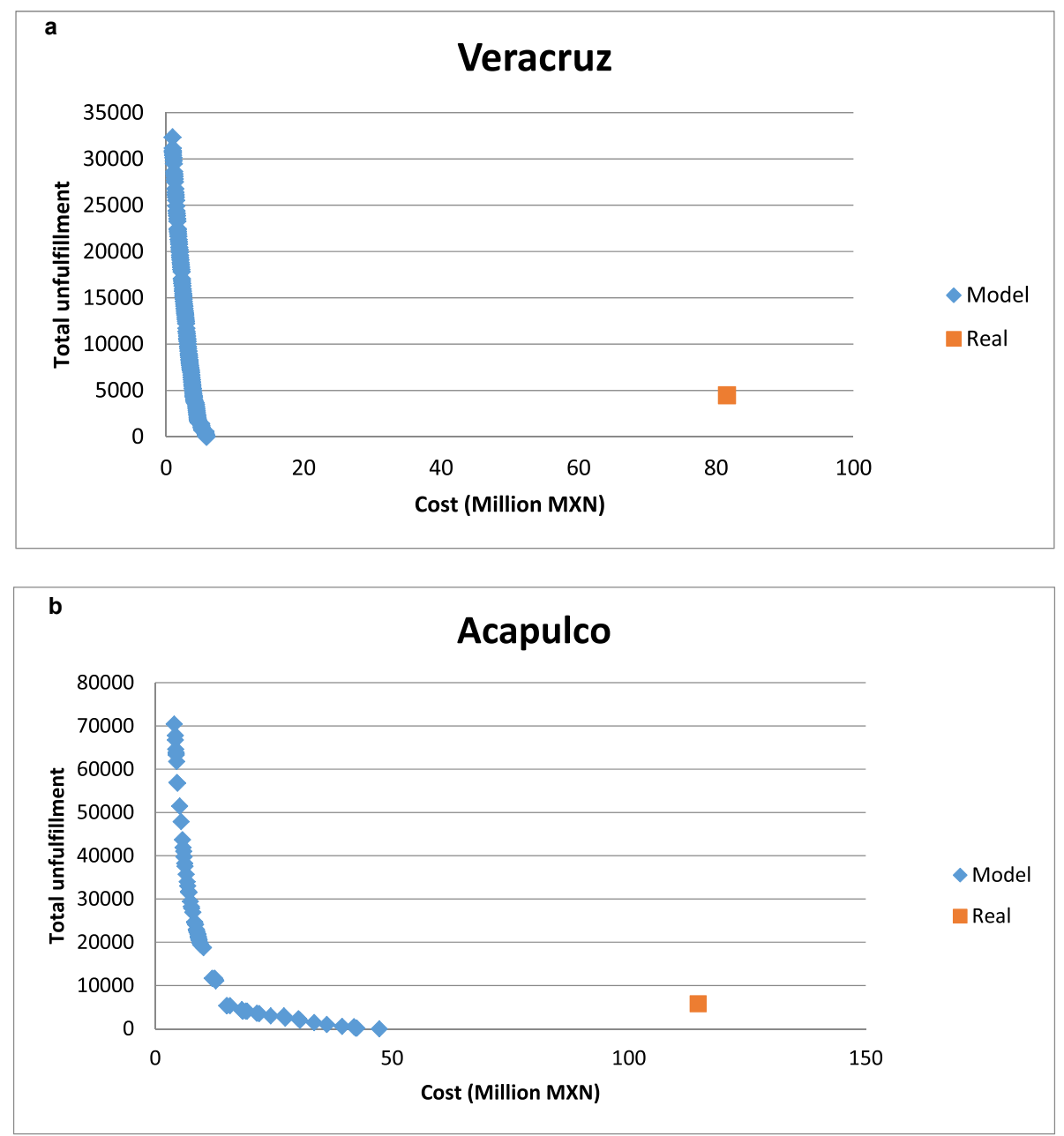

Fig. 9. (a). Comparison of the real activities in Veracruz with the Pareto frontier of the model. (b). Comparison of the real activities in Acapulco with the Pareto frontier of the model.

enhancing the participation of different organisations to provide better support, since there is no agency with the resources to completely manage disaster situations on its own. Optimisation can be a valuable tool to create an environment which allows different participants to work together and achieve better results.

The results obtained challenge the common practice in research of designing models for a single organisation. This paper demonstrates the need to manage and guide the organisations involved in disaster operations depending on the stage of the disaster. Using only the resources required can prevent waste and congestion. One of the main problems of the disaster management system in Mexico seems to be more related to the allocation of resources than to their availability. Additionally, the model showed the importance of using a dynamic approach. The evolution of the event has a direct impact in the deployment of organisations and the equitable delivery of products and services. The literature has focused on shortages of resources, but having access to the right expertise at the right time can significantly improve humanitarian logistics.

One limitation of the model is the need for centralised decisionmaking. The features of the organisations involved, along with jurisdictional challenges, should be carefully considered. Additionally, perfect information cannot be assumed given the chaotic circumstances experienced in disasters, pointing towards the need to incorporate imperfect information and/or resilience in future models. Future challenges and opportunities include the introduction of a routing and scheduling plan, dealing with the hierarchy of the organisations

Table 6

Comparison of solutions for disaster response in Veracruz-Boca del Río.

\begin{tabular}{|c|c|c|c|c|c|c|c|c|c|c|c|c|c|}
\hline \multirow[t]{2}{*}{ CASE } & \multirow[t]{2}{*}{ Sol } & \multirow[t]{2}{*}{ Cost (MXN) } & \multirow[t]{2}{*}{ Max agencies $\mathrm{p} /$ period } & \multicolumn{7}{|c|}{ Fill rate $(\%)$} & \multicolumn{2}{|c|}{ Max personnel used per period } & \multirow[t]{2}{*}{ Total trips } \\
\hline & & & & Food & Med & Ckit & Pkit & Hkit & $\mathrm{NH}$ & NS & Operative & Health & \\
\hline \multirow[t]{4}{*}{ VERACRUZ } & R1V114 & $4,259,706$ & 5 & 100 & 100 & 100 & 100 & 100 & 75.1 & 100 & 348 & 17 & 15 \\
\hline & MFR & $5,864,065$ & 5 & 100 & 100 & 100 & 100 & 100 & 100 & 100 & 388 & 17 & 9 \\
\hline & Agencies & $54,170,350$ & 9 & 85.07 & 100 & 84.4 & 84.4 & 84.4 & 100 & 100 & 2159 & 33 & 128 \\
\hline & Real & $81,575,576$ & 9 & 100 & 81.1 & 100 & 100 & 0 & 100 & 83.3 & 621 & 502 & 336 \\
\hline \multirow[t]{4}{*}{ ACAPULCO } & R1A46 & $25,461,547$ & 7 & 100 & 100 & 100 & 100 & 100 & 90.1 & 100 & 1534 & 127 & 122 \\
\hline & MFR & $46,725,583$ & 5 & 100 & 100 & 100 & 100 & 100 & 100 & 100 & 1215 & 127 & 221 \\
\hline & Agencies & $78,525,770$ & 11 & 93.4 & 97.5 & 92.3 & 92.3 & 92.3 & 100 & 100 & 3407 & 149 & 88 \\
\hline & Real & $114,750,000$ & 11 & 100 & 100 & 100 & 100 & 43.6 & 100 & 100 & 3803 & 137 & 924 \\
\hline
\end{tabular}


involved, and extending this system to introduce casualty transportation. Another aspect is the adaptation of the model to function with real time information and modify it to provide real time results. Phase integration can be a valuable step forward from this point onwards. Introducing collaborative models for disaster recovery, and developing integrated systems for disaster response and recovery are interesting opportunities for further research, especially considering the lack of research in the recovery stage. These systems could allow to smooth the transition across stages. Incorporating collaborative models for response and recovery can support the management of the shift in priorities among phases and ensure support is maintained for long-term operations.

\section{Acknowledgments}

The corresponding author wants to acknowledge the financial support received from the Consejo Nacional de Ciencia y Tecnología, México for the development of this research. Additionally, the authors of this paper would like to thank the two anonymous reviewers for their valuable comments, observations, and time.

\section{Appendix A. Supplementary data}

Supplementary data related to this article can be found at https:// doi.org/10.1016/j.ijpe.2018.07.023.

\section{References}

Adıvar, B., Mert, A., 2010. International disaster relief planning with fuzzy credibility. Fuzzy Optim. Decis. Making 9, 413-433.

AFP, 2010. No Rest for Flood-ravaged Mexico as New Storm Hits.

Altay, N., 2013. Capability-based resource allocation for effective disaster response. IMA J. Manag. Math. 24, 253-266.

Altay, N., Green, W.G., 2006. OR/MS research in disaster operations management. Eur. J. Oper. Res. 175, 475-493.

Anaya-Arenas, A.M., Renaud, J., Ruiz, A., 2014. Relief distribution networks: a systematic review. Ann. Oper. Res. 223, 53-79.

Arora, H., Raghu, T.S., Vinze, A., 2010. Resource allocation for demand surge mitigation during disaster response. Decis. Support Syst. 50, 304-315.

Balcik, B., Beamon, B.M., Krejci, C.C., Muramatsu, K.M., Ramirez, M., 2010. Coordination in humanitarian relief chains: practices, challenges and opportunities. Int. J. Prod. Econ. 126, 22-34.

Balcik, B., Beamon, B.M., Smilowitz, K., 2008. Last mile distribution in humanitarian relief. J. Intell. Transp. Syst. 12, 51-63.

Barbarosoğlu, G., Özdamar, L., Çevik, A., 2002. Decision Aiding: an interactive approach for hierarchical analysis of helicopter logistics in disaster relief operations. Eur. J. Oper. Res. 140, 118-133.

Beamon, B.M., Balcik, B., 2008. Performance measurement in humanitarian relief chains. Int. J. Public Sect. Manag. 21, 4-25.

CAAAAREM, 2009. Diagnóstico. Tipos de tráfico, Optimización de los Procesos Logísticos de importación y Exportación. Logistics, Services Network, S.A. de C.V. pp. 138.

Caunhye, A.M., Nie, X., Pokharel, S., 2012. Optimization models in emergency logistics: a literature review. Soc. Econ. Plann. Sci. 46, 4-13.

Chakravarty, A.K., 2011. A contingent plan for disaster response. Int. J. Prod. Econ. 134, 3-15.

Chang, M.-S., Tseng, Y.-L., Chen, J.-W., 2007. A scenario planning approach for the flood emergency logistics preparation problem under uncertainty. Transport. Res. Part E Logist. Transport. Rev. 43, 737-754.

Davis, L.B., Samanlioglu, F., Qu, X., Root, S., 2013. Inventory planning and coordination in disaster relief efforts. Int. J. Prod. Econ. 141, 561-573.

De la Torre, L.E., Dolinskaya, I.S., Smilowitz, K.R., 2012. Disaster relief routing: integrating research and practice. Soc. Econ. Plann. Sci. 46, 88-97.

Drabek, T.E., Hoetmer, G.J., 1991. Emergency Management: Principles and Practice for Local Government. International City Management Association.

Duhamel, C., Santos, A.C., Brasil, D., Châtelet, E., Birregah, B., 2016. Connecting a population dynamic model with a multi-period location-allocation problem for postdisaster relief operations. Ann. Oper. Res. 1-21.

Edrissi, A., Poorzahedy, H., Nassiri, H., Nourinejad, M., 2013. A multi-agent optimization formulation of earthquake disaster prevention and management. Eur. J. Oper. Res. 229, 261-275.

EOS, 2013. In: Acapulco, Mexico Started a New Flood.

García, N., Méndez, K., Reyes, R., Marin, R., 2015. Impacto Socioeconómico de los
Principales Desastres Ocurridos en la República Mexicana en 2013. CENAPRED, México, D.F.

Google_Earth, 2016. Mexico.

Gupta, S., Starr, M.K., Farahani, R.Z., Matinrad, N., 2016. Disaster management from a POM perspective: mapping a new domain. Prod. Oper. Manag. 25, 1611-1637.

Holguín-Veras, J., Jaller, M., Wassenhove, L.N.V., Pérez, N., Wachtendorf, T., 2014. Material convergence: important and understudied disaster phenomenon. Nat. Hazards Rev. 15, 1-12.

Holguín-Veras, J., Pérez, N., Jaller, M., Van Wassenhove, L.N., Aros-Vera, F., 2013. On the appropriate objective function for post-disaster humanitarian logistics models. J. Oper. Manag. 31, 262-280.

Huang, K., Jiang, Y., Yuan, Y., Zhao, L., 2015. Modeling multiple humanitarian objectives in emergency response to large-scale disasters. Transport. Res. Part E Logist. Transport. Rev. 75, 1-17.

INEGI, 2010. México en Cifras.

Kaiser, R., Spiegel, P.B., Henderson, A.K., Gerber, M.L., 2003. The application of geographic information systems and global positioning systems in humanitarian emergencies: lessons learned, programme implications and future research. Disasters 27, $127-140$.

Kumar, S., Havey, T., 2013. Before and after disaster strikes: a relief supply chain decision support framework. Int. J. Prod. Econ. 145, 613-629.

Kunz, N., Reiner, G., Gold, S., 2014. Investing in disaster management capabilities versus pre-positioning inventory: a new approach to disaster preparedness. Int. J. Prod. Econ. 157, 261-272.

Lassiter, K., Khademi, A., Taaffe, K.M., 2015. A robust optimization approach to volunteer management in humanitarian crises. Int. J. Prod. Econ. 163, 97-111.

Lee, I., Lee, K., Torpelund-Bruin, C., 2011. Raster voronoi tessellation and its application to emergency modeling. Geo-spat. Inf. Sci. 14, 235-245.

Lei, L., Pinedo, M., Qi, L., Wang, S., Yang, J., 2015. Personnel scheduling and supplies provisioning in emergency relief operations. Ann. Oper. Res. 235, 487-515.

Liberatore, F., Ortuño, M.T., Tirado, G., Vitoriano, B., Scaparra, M.P., 2014. A hierarchical compromise model for the joint optimization of recovery operations and distribution of emergency goods in Humanitarian Logistics. Comput. Oper. Res. 42, $3-13$.

Mete, H.O., Zabinsky, Z.B., 2010. Stochastic optimization of medical supply location and distribution in disaster management. Int. J. Prod. Econ. 126, 76-84.

Miettinen, K., Ruiz, F., Wierzbicki, A.P., 2008. Introduction to multiobjective optimization: interactive approaches. In: Branke, J., Deb, K., Miettinen, K., Słowiński, R. (Eds.), Multiobjective Optimization. [electronic resource]: Interactive and Evolutionary Approaches. Springer Berlin Heidelberg, Berlin, Heidelberg 2008.

Nogami, T., Yoshida, F., 2014. Disaster myths after the Great East Japan Disaster and the effects of information sources on belief in such myths. Disasters 38, s190-s205.

Özdamar, L., Ekinci, E., Küçükyazici, B., 2004. Emergency logistics planning in natural disasters. Ann. Oper. Res. 129, 217-245.

Ozdamar, L., Ertem, M.A., 2015. Models, solutions and enabling technologies in humanitarian logistics. Eur. J. Oper. Res. 244, 55-65.

Ransikarbum, K., Mason, S.J., 2016a. Goal programming-based post-disaster decision making for integrated relief distribution and early-stage network restoration. Int. J. Prod. Econ. 182, 324-341.

Ransikarbum, K., Mason, S.J., 2016b. Multiple-objective analysis of integrated relief supply and network restoration in humanitarian logistics operations. Int. J. Prod. Res. 54, 49-68.

Rennemo, S.J., Rø, K.F., Hvattum, L.M., Tirado, G., 2014. A three-stage stochastic facility routing model for disaster response planning. Transport. Res. Part E Logist. Transport. Rev, 62, 116-135.

Rodríguez-Espíndola, O., Albores, P., Brewster, C., 2016. GIS and optimisation: potential benefits for emergency facility location in humanitarian logistics. Geosciences (Switzerland) 6.

Rodríguez-Espíndola, O., Albores, P., Brewster, C., 2018. Decision-making and operations in disasters: challenges and opportunities. Int. J. Oper. Prod. Manag. https://doi.org/ 10.1108/IJOPM-03-2017-0151.

Rodríguez-Espíndola, O., Gaytán, J., 2015. Scenario-based preparedness plan for floods. Nat. Hazards 76, 1241-1262.

Roh, S., Pettit, S., Harris, I., Beresford, A., 2015. The pre-positioning of warehouses at regional and local levels for a humanitarian relief organisation. Int. J. Prod. Econ. 170 (Part B), 616-628.

Savas, E.S., 1978. On equity in providing public services. Manag. Sci. 24, 800-808.

SEDENA, 2010. In: OPTVA, S. (Ed.), Appendix of the Interview, pp. 4 México, D.F.

SEGOB, 2006. ACUERDO por el que se emite el Manual de Organización y Operación del Sistema Nacional de Protección Civil, México. pp. 112.

Sha-lei, Z., Nan, L., Yong, Y., 2014. Coordinating efficiency and equity in disaster relief logistics via information updates. Int. J. Syst. Sci. 45, 1607-1621.

Tatham, P., Kovacs, G., 2010. The application of "swift trust" to humanitarian logistics. Int. J. Prod. Econ. 126, 35-45.

Tirado, G., Javier Martin-Campo, F., Vitoriano, B., Teresa Ortuno, M., 2014. A lexicographical dynamic flow model for relief operations. Int. J. Comput. Intell. Syst. 7 , 45-57.

Whybark, D.C., 2007. Issues in managing disaster relief inventories. Int. J. Prod. Econ. $108,228-235$

World_Bank, 2013. Mexico Overview. 